\title{
The Contingent Role of Interproject Connectedness in Cultivating Open Source Software Projects
}

\begin{abstract}
The quest for having a good understanding of the key to successful open-source software (OSS) development continues to motivate research. Aligned with works that build on the notion that an OSS development is tightly interrelated with its social environment (i.e., the OSS community), this research examines the relationship between interproject structure and OSS project success. We conceive OSS project success to be reflected in two forms, namely popularity (i.e. market success) and knowledge creation (i.e. technical success). We surveyed the OSS literature and theorized a contingent role of interproject connectedness in cultivating OSS projects. We posit (1) OSS project with more structural holes achieves higher popularity; (2) OSS project with fewer structural holes yields higher knowledge creation; and (3) these two relationships are enhanced with an increase in project maturity. Using a dataset longitudinally collected from SourceForge.net, we found that OSS projects with sparse connectedness to be more popular, which was prominent for those OSS projects at the mid-mature stage. Cohesive connectedness helped the OSS project, irrespective of its maturity, achieves higher knowledge creation. Findings from the study can provide a structural purview to identify OSS projects that are more likely to be successful.
\end{abstract}

Keywords: open source software, interproject connectedness, maturity, popularity, knowledge creation 


\section{Introduction}

Open-source software (OSS) development forges, such as Sourceforge and Github, are an integral part of software innovation. A recent report estimates that the economic value of OSS development can exceed US\$32 billion by the year $2023^{1}$. Major technological titans, such as Amazon, Facebook, Apple, Alibaba, and Microsoft ${ }^{2}$, have also tapped on the OSS development forges for their software innovation. Unique to the OSS development forges, such as Sourceforge and Github, is that OSS projects are formed by globally distributed people. This assumingly enables the projects to gain access to an unlimited pool of IT talents. Unfortunately, fewer than desired OSS projects achieve success (Chengalur-Smith and Sidorova 2003; Lin et al. 2017). OSS project success can be reflected in the forms of popularity (i.e. market success) and knowledge creation (i.e. technical success) (Crowston et al. 2007; Subramaniam et al. 2009). The question is then what kind of OSS projects is more likely to be successful?

To gain an understanding of a key to successful open-source software (OSS) development, it is important to recognize that an OSS project is tightly interrelated with the OSS community where the supply of IT talents is from. Elaborately, the resources for software development, such as source codes and developers, are mobilized across projects (von Hippel and von Krogh 2003). Source codes are freely revealed to the public, which promotes the diffusion of innovation. Such freely revealed source codes (i.e., knowledge) are circulated through the connectedness of the OSS projects, i.e., shared developers across projects. Developers can freely contribute to multiple projects that they like (Grewal et al. 2006; Tan et al. 2007) and they are not required to

\footnotetext{
${ }^{1} \mathrm{https}$ ://www.marketresearchengine.com/open-source-services-market [Last access 10th Sep 2019]

${ }^{2}$ https://news.microsoft.com/2018/06/04/microsoft-to-acquire-github-for-7-5-billion/ [Last access 10th Sep 2019]
} 
commit themselves exclusively to a single project ${ }^{3}$. The inter-connected OSS development projects, made possible by common IT talents, thus facilitate the sharing of knowledge and expertise thereby leading to OSS project success (Conaldi et al. 2012; Hahn et al. 2008; Singh et al. 2011a, 2011b; Singh and Tan 2010).

To the best of our knowledge, the structural characteristic of an OSS project (i.e., connectedness to other projects) has been less studied despite its importance ${ }^{4}$. We have found three studies looking at the connectedness among OSS projects: Grewal et al. (2006) considered network centrality, Singh (2010) looked at macro-level network attributes (e.g., clustering coefficients and path lengths), and Singh et al. (2011a) deliberated on repeat ties and Burt's network constraint to predict OSS project success. The fundamental argument in these studies is social capital, more specifically, structural social capital (Grewal et al. 2006; Singh 2010; Singh et al. 2011a). The structural social capital only implies that information access hinges upon the configuration of network structure and an OSS project's connectedness to others give the project access to a certain type of information. However, how it could translate to project success in terms of gaining popularity and creating knowledge remains unclear. A primary reason is the different trajectories of the popularity and knowledge creation.

A popular OSS project (i.e. market success) is able to reach out to more users in the market by meeting users' various requirements in OSS features and functionalities. Thus, to attain the market success, the OSS project needs to enrich its spectrum of generated ideas and have more heterogeneous contributors who, as a whole, promote creative abrasion (Harrison and Klein

\footnotetext{
${ }^{3}$ Isolated developers (i.e., developers with a single project) exist in the OSS context (Gao and Madey 2007), and developers do tend to interact only with prominent developers (Shen and Monge 2011). Hence, not all projects are interlinked or intensively interlinked. In this research, we focus on projects that are interconnected through common contributors.

${ }^{4}$ Prior studies have identified several contributing factors for OSS project success, which include project-specific characteristics such as the types of OSS license, the leader-follower relationship, the availability of company sponsorship, the project activity, and the popularity of programming language in which an OSS is developed (Jiang et al. 2019).
} 
2007; Ren et al. 2016; Van Knippenberg et al. 2004). Different from earning market success, the knowledge creation (i.e., technical success) depends more upon the homogenous resources. Elaborately, an OSS project with homogeneous contributors can benefit from consistent beliefs about its development and innovation priorities (Ren et al. 2016; Van Knippenberg et al. 2004). From the software development perspective, strong team cohesion is conducive to both the delivery and the technological quality of software projects (Lindsjørn et al. 2016). In short, the heterogeneous resource is in favor of market success and the homogeneous resource promotes technical success.

The proliferation of heterogeneous or homogeneous resources is implicated in the network structure, which bases on two contesting theories, namely structural holes theory and network closure theory (Burt 1992; Coleman 1988). The proponents of structural holes theory believe the vertex at brokerage positions have access to a great variety of information, which brings about heterogeneity in resources (Burt 1992). However, the network closure theory argues the closed network can cultivate coherent beliefs and collective actions, which is more liable to foster homogeneity in research (Gargiulo and Benassi 2000). To this end, applying these two theoretical contentions into the OSS context, we posit an overarching proposition that the social network structure (from the OSS project interconnectedness) plays a contingent role in facilitating OSS project success. Particularly, considering two forms of OSS project success (Crowston et al. 2007; Subramaniam et al. 2009), we propose:

1. OSS projects with more structural holes can achieve better market success; however, 2. OSS projects with fewer structural holes can achieve better technical success.

We further develop the proposition by recognizing that while the network structure prioritizes the position of the OSS project for accessing resources like contributors (Zaheer and 
Soda 2009), how far these network-related benefits can be harnessed to contribute OSS project success hinges upon the extent to which that OSS project can synthesize (Daniel et al. 2013; Setia et al. 2012). Previous studies contended that an OSS project's maturity ${ }^{5}$ (i.e., whether it is in a pre-beta, beta, or post-beta phase) was indicative of abundant resource allocation of that project (Garriga et al. 2011). Thus, we argue the OSS project maturity enhances the main effects in the preceding paragraphs. That means the maturity of the OSS project could potentially moderate the relationships between OSS project interconnectedness (as manifested by structural holes) and OSS performance (as manifested by market success and technical success).

By empirically analyzing a considerable size of the longitudinal dataset from Sourceforge.net, this work makes several contributions to the OSS literature, which we introduce two of them here. First, we productively extend the current OSS literature by conceiving that the OSS interproject connectedness has a contingent impact on OSS project success, which varies in terms of market success or technical success. By doing so, this research adds to the few OSS studies that take a social capital perspective to OSS development (Grewal et al. 2006; Singh 2010; Singh et al. 2011a) by extending the understanding that an OSS project can achieve market success through gaining more structural holes while another OSS project situated in cohesive network is more liable to attain technical success. Second, we provide evidence that OSS project maturity helps to synthesize the external resource, e.g. contributors or their efforts, but not at all aspects. Only the OSS projects, which progress from very nascent stage to developmental stage and are saturated with abundant structural holes, can benefit from maturity for market success.

\footnotetext{
${ }^{5}$ OSS project age is an adjacent measure of maturity. Assuming that organizations accumulate innovation capabilities at the same rate, older organizations should outperform the younger ones (Schoonhoven 2015). However, this assumption has been challenged by several studies because an organization's age may not be a reliable proxy for maturity in terms of innovation capabilities (Coad et al. 2016). We therefore believe that innovation maturity is a more appropriate measurement of OSS project maturity.
} 
This rectifies previous literature that has disproportionately esteemed the positive role of maturity in promoting OSS project success (Daniel et al. 2013; Setia et al. 2012).

\section{Relevant OSS Literature}

The OSS research attracts considerable attention due to its intriguing and counterintuitive model of innovation, in which large numbers of talented developers voluntarily contribute to the creation, maintenance, and support of a public good (Lerner and Tirole 2002). Inspired by such a phenomenon, a line of early studies deliberated the individual motivation to participate in or contribute to the OSS project. These works discussed various participatory motives, such as enjoyment, self-efficacy, need for competence, community reputation, status, learning opportunities, and social identity among other motivational factors (Shah 2006; Feller et al. 2006). Leading from and further extending from these works, von Hippel and von Krogh (2003) proposed a model of innovation to summarily explain individual motives in participating in OSS innovation activities. The authors found that although innovators do not gain proprietary benefit from the OSS per se, the free revealing (of source codes) promotes the innovation diffusion and eventually benefits the innovators from the diffusion of such innovation-related information. In other words, the return on innovation results from the participation per se.

Another stream of OSS research focuses on the "success factor" of OSS projects (Subramaniam et al. 2009; Daniel et al. 2013; Garriga et al. 2011; Stewart et al. 2006). Several software-specific characteristics are attributed to the OSS project success, such as OSS license (Subramaniam et al. 2009), software type (Daniel et al. 2013), team size (Garriga et al. 2011), and organizational sponsorship (Stewart et al. 2006). These works have paid primary attention to the intrinsic characteristics of the OSS project and little on the structural characteristic of it with the OSS community (interconnectedness) where the supply of IT talents is from. 
As introduced earlier, OSS development involves orchestrated and collective action among the contributors who are related through interaction, thereby forming a network of relationships and ties (Hahn et al. 2008). Prior literature classified these contributors into two groups: the development group and the management group (Subramaniam et al. 2009). While the development group consists of individuals who mainly contribute to the software coding, the management group consists of individuals who created the OSS project and make the decisions on version releases (also known as product administrators or leaders). The OSS projects are interconnected through the shared contributors, and meanwhile, the innovation-related resources are mobilized via such connectedness.

Although the OSS projects are interconnected in nature, not many studies deliberated the structural characteristic of an OSS project (i.e., inter-connectedness to other projects) and discussed its impact on OSS project success (exceptions being Grewal et al. 2006; Singh 2010; Singh 2011a). Grewal et al. (2006) applied network centrality to predict the OSS project success, which might be unfeasible in practice because individual network centrality heavily depended on how other vertexes, i.e. OSS projects, connected in the whole network. Singh (2010) applied macro-level network attributes, e.g. clustering coefficients, path lengths, and their interactions to examine their impacts on the success of OSS projects. However, this work did not consider the network structure with respect to the project level, which restrained the implications for managing an individual OSS project. Singh et al. (2011a) employed repeat ties and Burt's network constraint to reflect internal and external cohesion of an OSS project and unveiled an inverted U-shape between external cohesion and OSS project performance (measured as number of CVS commits). However, measuring the OSS project success by the number of CVS commits is controversial because a large number of CVS commits may also imply poor software quality 
(Bird et al. 2009). To fill these gaps, we (1) analyze an OSS project's connectedness in an ego network in lieu of whole network to avoid the interdependency, and (2) measure the OSS project success via two forms, i.e. market success and technical success. The prospective findings can inform OSS projects on how to strategically position themselves to achieve success. More details are given in the subsequent sections.

In addition, as depicted previously, there is room for improvement of the theoretical backbones of the abovementioned three exceptional works (Grewal et al. 2006; Singh 2010; Singh 2011). Elaborately, the structural social capital, i.e. their theoretical basis, only accounts for how network structure affects the variance of information access but not the innovation outcome (Burt 1992). Thus, we attempt to further theorize the role of interproject connectedness in OSS project success. We argue the configuration of network structure not only affects the information access but also, as a consequence, polarizes the nature of the accessible resources, i.e. heterogeneity vs. homogeneity (Nerkar and Paruchuri 2005; Ahuja 2000). The latter characterizes the OSS project success, whose theoretical inference is elaborated on the hypotheses development section.

Besides resource accessibility, how much such resources can be synthesized should also significantly implicate an OSS project's success (Daniel et al. 2013; Setia et al. 2012). Previous literature employed the OSS project maturity as a proxy indicator reflecting the synthesis capability. More specifically, mature projects with better project governance can effectively raise the productivity of the OSS development teams (Setia et al. 2012). Compared to the projects at a nascent stage, the mature projects have established team cognition and shared understanding, which alleviated the unnecessary misunderstanding and disagreement in the course of OSS development (He et al. 2007). The advanced code management in mature project is also helpful 
to internalize the knowledge and information extravagated from the other project (Daniel et al. 2013; Setia et al. 2012). In sum, the maturity of the OSS project facilitates better inoculation of various resources including the team of contributors, their knowledge, experiences, and ideas. Thus, OSS project maturity moderates the relationship between the interproject connectedness and its success. We will give theoretical deduction in detail in the next section.

\section{Hypotheses Development}

In the OSS community, an OSS project's connectedness to other projects via common contributors define its ego network. Visually, an OSS project's ego network is the central node (ego), and connected OSS projects (i.e., other OSS projects with ties to the ego) are the neighboring nodes (Everett and Borgatti 2005). Thus, whether and to what extent an OSS project has access to resources depends on its position in the network woven by its contributors. To this end, social network analysis reveals the relationship between the network position and structure and resident actors' access to resources (Ahuja 2000; Austin 2003; Balkundi et al. 2007; Beckman and Haunschild 2002; Harrison and Klein 2007). Among these studies, the concept of a structural hole, which depicts a network structure without direct contact with or ties between two or more nodes, is heavily discussed. By applying this concept to the OSS context, we ask whether the presence of more structural holes in an inter-project network is beneficial to OSS project success despite the controversy surrounding this concept in the general management literature.

Applying the structural hole theory in the OSS context, we can infer that OSS projects connected to other projects via contributors with non-redundant (non-overlapping) external network ties have access to more variety of resources (Austin 2003; Beckman and Haunschild 2002; Harrison and Klein 2007). This proposition accords to the thesis that socioeconomic opportunities increase with the number of structural holes in an ego network due to increased 
access to diversified information (Eagle et al. 2010). Conversely, in the absence of structural holes, nodes in an ego network are less likely to develop new ideas (Balkundi et al. 2007). When contributors draw from different pools of resources, they are liable to have conflicting viewpoints and opinions and can, therefore, deliver more creative products than those who draw from the same pool of resources (Harrison and Klein 2007; Jackson et al. 1995).

However, on the other hand, Podolny and Baron (1997) argued that "a cohesive network [network with few structural holes] conveys a clear normative order within which the individual [OSS project] can optimize performance, whereas a diverse ... network [network with many structural holes] exposes the individual to conflicting preferences and allegiances within which is much harder to optimize" (p. 676). In a network with many structural holes, organizations must reconcile opposing views by thoroughly processing information that could reduce OSS innovation performance (Van Knippenberg and Schippers 2007). In other words, an organization (i.e., an OSS project in our case) with many structural holes faces potential malfeasances (Ahuja 2000), such as coordination difficulty (Balkundi et al. 2007) and decreased production, even though conflict can contribute to a more complete and careful analysis of the task at hand and make better decision.

Conversely, interconnected nodes with few structural holes benefit from shared resources and beliefs about project priorities and how the work should be carried about. This viewpoint aligns with the premise that OSS contributors are motivated by knowledge creation. Tan et al. (2007) studied OSS developers' ego networks and found that OSS developers at brokerage positions may not benefit more than the rest of the community because they incur the cost of sharing and relating knowledge across heterogeneous projects. This empirical evidence echoes arguments in favor of a cohesive network structure (i.e. few structural holes). 
To reconcile these views, Ahuja (2000) evaluated competing for hypotheses on the consequences of the number of structural holes on an organization's innovation performance. The author observed that for an inter-organizational network that is focused on collaboration, cohesive networks (i.e., those with few structural holes) are likely beneficial because they foster the development of the fine-grained resource. However, organizations that rely on diverse resources likely benefit from many structural holes. The two seemingly contradictory viewpoints can be reconciled by considering various aspects of OSS project success. OSS project success cannot be evaluated using a single criterion but must be considered in light of multiple dimensions representing various stakeholders. For instance, the number of downloads is a widely adopted index of market success among OSS projects, but this index may be biased due to the nature of the projects ${ }^{6}$ (Crowston et al. 2006). Likewise, the number of concurrent versioning system (CVS) commits also represents OSS performance because it describes the developers' vitality; however, higher commit numbers may also indicate poorer software quality (Crowston et al. 2006).

Subramaniam et al. (2009) employed a multidimensional construct to represent OSS project success. They found the same antecedents exert a different impact on different aspects of OSS project success. Building on this understanding, we consider OSS project success based on two indicators: popularity and knowledge creation. The former reflects the interest in the OSS project by the users at large, which SourceForge.net bases on the number of OSS downloads and OSS project site and page visits (Setia et al. 2012). The latter reflects contributors' developmental intensity, which SourceForge.net bases on the number of CVS commits, the frequency of the released files (developers' output), and project administrators' activity levels (Crowston et al.

\footnotetext{
${ }^{6}$ In most cases, OSS projects designed as end-user applications are downloaded more often than those that serve as fundamental units, such as game engines or frameworks.
} 
2006). In the innovation management literature, these two dimensions are referred to as market success and technical success respectively (Peng et al. 2013). Next, we will examine these two performance types and deduce how the configuration of interproject connectedness and OSS project maturity influence them.

\subsection{The Controversy Surrounding Network Theory}

OSS projects' ego networks comprise common contributors' links and ties, which facilitate information and resource exchange. As noted previously, we consider OSS projects' ego networks based on common administrators and common developers. This approach echoes previous studies that categorized OSS project participants according to various roles (Crowston and Howison 2006; Aberdour 2007; Setia et al. 2012; Jiang et al. 2019). As OSS project leaders, administrators play an essential role in setting up projects, communicating with the OSS community, and recruiting and managing developers (Heckman et al. 2007). Unlike developers, who contribute specialized technical knowledge, administrators are often generalists who must be familiar with projects' overall development and ability to integrate specialized knowledge. They govern and motivate developers to achieve a common goal: innovation development (Chen and Dietrich 2009). Administrators with preexisting developer contacts (e.g., from managing other projects) are more likely to attract developers to a focal project (Hahn et al. 2008), which could suggest the importance of administrators' connection to other projects. As primary contributors of innovation, developers who participate in multiple projects provide two knowledge benefits to a focal project: resource sharing and knowledge spillover (Ahuja 2000; Grewal et al. 2006). Resource sharing allows developers to integrate knowledge within projects, whereas knowledge spillover provides project participants with information about design 
problems and experience, failed and successful approaches, breakthroughs, and opportunities (Ahuja 2000).

An OSS project ego network with many structural holes has greater access to diversified information, which is an essential resource in information retrieval activities and enables participants to control information dissemination (Nerkar and Paruchuri 2005). Administrators perform several vital functions, including communicating information about their projects to the OSS community (Heckman et al. 2007). Increasing the number of structural holes in an OSS project's ego network can enhance project visibility (Shipilov 2009). Administrators understand the broader interests of other projects' contributors and make strategic decisions to popularize particular OSS projects. For instance, administrators can reprioritize tasks in the pipeline because certain features are popular in other projects. Likewise, developers who participate in multiple projects have close contact with the diversified demands of various OSS projects' users. Consequently, developers implement a variety of demands when developing the focal OSS, which attracts broader interest in the project. Accordingly, even though resource mobilization mechanisms vary across projects according to participants' roles, their consequences should be convergent. Thus, we present the following hypothesis:

Hypothesis 1: An OSS project with a higher extent of structural holes in its ego networks [i.e., constructs based on the focal project's connections with other projects due to (a) common administrators or (b) common developers] is associated with higher popularity [i.e. market success].

OSS project ego networks with many structural holes may face communication and coordination challenges. Considering patenting frequency in the chemical industry, Ahuja (2000) observed that networks with many structural holes exhibited decreased innovation output in 
terms of the number of patents filed. In addition, in a study of workgroups in a global organization, Cummings and Cross (2003) observed that workgroups with many structural holes exhibited diminished performance efficiency and schedule and budget adherence. Although increasing an OSS project's popularity is a matter of generating a spectrum of ideas based on shared knowledge and learning from other projects' failures and successes, OSS project development involves more than possessing such knowledge. Administrators' and developers' experiences working on other projects must be coordinated and integrated during software development (Tullio and Staples 2013). From the social categorization perspective in the network closure theory, a cohesive network with interconnected OSS projects (i.e., fewer structural holes) converges mental models related to how administrators and developers should work together; this, in turn, may facilitate innovation output (Ren et al. 2016; Van Knippenberg et al. 2004). In addition, organizations with few structural holes benefit from access to shared resources and knowledge spillovers, as opportunism is likely to be reduced. This enables contributors to efficiently leverage shared intellectual property to develop OSS. For these reasons, we postulate as follows:

Hypothesis 2: An OSS project with the lower extent of structural holes in its ego networks [i.e., constructs based on the focal project's connections with other projects due to (a) common administrators or (b) common developers] is associated with higher knowledge creation [i.e. technical success].

\subsection{Maturity of the OSS Project}

How much resources from the interconnected projects can contribute to an OSS project success hinges on the internalization capability of the focal project (Zahra and George 2002). It is recognized that new product teams face the dilemma of limited resources or capital, which 
restricts their capability to synergize the internal dynamics with external resources (Patel et al. 2015; Schoonhoven 2015). Teams at an early phase need to confront the cost of learning new rules, the cost of creating new roles (in the workgroup), the social relationship among internal stakeholders, and the ability to establish robust ties with external stakeholders (Gulati and Higgins 2003; Li et al. 2008). The accumulated cost restricts the growth of innovation, which results in the high likelihood of mortality in their early phases of development. If this is so, participants in immature OSS projects with advantageous resource access may still not be able to appropriately utilize such resource to boost their innovation output. Conversely, established teams comprising members with long-standing relationships would outperform "fresh" teams (Harrison et al. 1998, 2002) because the former can more easily absorb external information into their innovation output. That is, the dysfunctional situation caused by transformation capability can be alleviated as the OSS project matures, which aptly resonates with the idea of the product lifecycle stage.

By referring to prior literature (Daniel et al. 2013; Setia et al. 2012), we employ the threephase maturity model (pre-mature phase, mature phase, and post-mature phase) to assess an OSS project's maturity. This model not only reflects its history in past collaborations but also indicates the extent to which the contributions from multiple people have been integrated into the software itself. In other words, OSS projects at a more mature phase can be inferred to have a higher capability of knowledge assimilation. Mature projects attract contributors with their normative governance mechanism, well-written codes, and stable collaboration structure, which also provide better stages to make their contributions more effective and yield the innovation output (Setia et al. 2012). These characteristics clearly echo the innovation mechanism in OSS, where the contributors primarily benefit from the participation of OSS development (von Hippel 
and von Krogh 2003). Therefore, mature projects can attract more dedicated contributors because their compensation which results from innovation activities, is higher than that from immature ones. Therefore, we infer that mature projects can better internalize and apply the resource to the innovation output. Moreover, this impact can be subsequently accentuated because these qualified contributors can attract more contributors and resources (Daniel et al. 2013). In other words, it arouses the network effect.

Operationally, the OSS developmental stages have been employed in several studies to assess the theoretical boundary between various precursor factors and OSS project success (Daniel et al. 2013; Setia et al. 2012; Stewart and Gosain 2006; Subramaniam et al. 2009). Therefore, we argue that the ability to leverage information in an OSS project and facilitate its success is contingent on its development stage (i.e., maturity level). OSS projects at early development stages cannot properly transform resources into their project assets. An OSS project's development stage, which indicates its maturity, determines whether its participants can effectively incorporate the resources accessed from the community into innovation activities (Daniel et al. 2013; Setia et al.2012). Participants in mature OSS projects may successfully incorporate the resources sourced from various stakeholders into OSS development. On the contrary, participants in less mature OSS projects may not yet have a well-established process of knowledge assimilation. In OSS projects with many structural holes, maturity exerts an influence on their participants' ability to internalize the diversified resources into the innovation outputs. Diversified resources could include various user demands, distinctively inspirational ideas, novel technologies, etc., from other OSS projects (Nerkar and Paruchuri 2005; Shipilov 2009). For those OSS projects residing in the cohesive network, the maturity grants their participants the ability to effectively inoculate the resources into project development because of the relatively 
robust knowledge base (Autio et al. 2000). Jones (2006) argued that mature organizations emphasized knowledge exploitation rather than exploration. Knowledge exploitation entails the effective application of resources by emphasizing the "refinement, routinization, production and elaboration of existing experience" (Holmqvist 2003, page 99). Collectively, we posit:

Hypothesis 3: The positive relationship between the number of structural holes and popularity will be stronger in projects in mature phases.

Hypothesis 4: The negative relationship between the number of structural holes and knowledge creation will be stronger in projects in mature phases.

\section{Research Methodology}

\subsection{Background and Ego network}

We conducted a longitudinal investigation using the data set available on SourceForge.net. We collected the data twice in 18 months to separate the antecedents from their outcomes and to allow for a more extended observation period to determine the effect of brokerage positions on popularity and knowledge creation. The selection of the 18-month time frame is referred to as the OSS project's progressive period suggested in the previous OSS literature (Crowston et al. 2012; Ghosh 2006; Daniel et al. 2018). Furthermore, we excluded OSS projects with the statuses "inactive" and "planning" because such projects have not been released to the public or the participants have made few contributions to the OSS projects.

With the data set obtained, we constructed each OSS project's ego network to discover each project's position in the overarching network. Each OSS project was recorded as a vertex, all of which were linked to one another through contributors across the various project categories ${ }^{7}$.

\footnotetext{
${ }^{7} 18$ main project categories were found on SourceForge at the time of data collection: development, games, Internet, scientific, system, education, desktop, communications, security, editors, multimedia, formats_and_protocols, database, office, printing, religion, and mobileapps.
} 
Such a network is defined as an affiliation network in prior literature (Wasserman and Faust 1994). In our research setting, OSS projects are linked with each other if they have a common contributor, such as an administrator or developer, in multiple project categories. As previously mentioned, in previous OSS literature, contributors engaging in OSS projects are sorted into various roles (Aberdour 2007; Crowston and Howison 2006; Setia et al. 2012). Hence, we constructed the two networks affiliated with common administrators and developers. In such networks, the vertexes are OSS projects and are connected because of the shared contributors (i.e., administrators or developers respectively).

\subsection{Dependent Variables}

We employed the OSS project's traffic intensity and development intensity to manifest its popularity and knowledge creation. These two measurements were developed by referring to SourceForge.net's indexes and prior literature. In particular, SourceForge.net employed a composite index (i.e., "Most Active Projects") to reflect each OSS project's latest-7-day vitality ${ }^{8}$. Previous OSS literature includes attempts to evaluate the OSS project's performance via multiple dimensions (e.g., number of downloads, number of CVS commits, and size of developer team) (Crowston et al. 2006; Healy and Schussman 2003; Subramaniam et al. 2009). By jointly considering the practice in SourceForge.net (7-day window) and the proposition in the previous literature (multidimensional measurements of OSS project success), we developed two measurements that were composed of three components. Traffic intensity included downloading intensity (the extent of adoption among the end-users), logo-hitting intensity (the extent of visits to the project page), and page-view intensity (the depth of visits within the project page). Development intensity was composed of CVS commits (the extent of contribution from

\footnotetext{
${ }^{8}$ Sourceforge.net changed the whole design at this moment (last accessed April 11, 2019). We relied on "web.archive.org" to access the historical version of sourceforge.net in June 2009.
} 
contributors to the focal OSS project), the history of recently released files (the extent of the overall contributors' recent vitality), and administrators' login information (the extent of administrators' activities). The detailed equations are listed below, and the descriptions of the components are given in Table 1.

$$
\begin{aligned}
& T R F_{i t}=\left(\ln \left(P 7 D T_{i t}+1\right) / \ln \left(H D T_{t}+1\right)+{ }^{\ln \left(P 7 L T_{i t}+1\right) / \ln \left(H I L T_{t}+1\right)}+{ }^{\ln \left(P 7 S T_{i t}+1\right) / \ln \left(H I S T_{t}+1\right)}\right) / 3 \\
& D E V_{i t}=\left(\ln \left(P 7 C T_{i t}+1\right) / \ln \left(H I C T_{t}+1\right)+D A L F R_{i t} / 100+D A D M L_{i t} / 100\right) / 3
\end{aligned}
$$

\begin{tabular}{|l|l|}
\hline $\begin{array}{l}\text { Components } \\
\text { name }\end{array}$ & Description \\
\hline TRF $_{\text {it }}$ & $\begin{array}{l}\text { Traffic intensity of project } i \text { at time } t \text {. This variable was defined by SourceForge, which } \\
\text { included downloading, logo hitting, and site-hitting traffic. }\end{array}$ \\
\hline P7DT $_{\text {it }}$ & The total downloading counts of project $i$ in the last 7 days since time $t$ \\
\hline HIDT $_{\mathrm{t}}$ & The most downloaded counts at time $t$ \\
\hline P7LT $_{\text {it }}$ & The total logo hit counts of project $i$ in the last 7 days since time $t$ \\
\hline HILT $_{\mathrm{t}}$ & The most logo hit counts at time $t$ \\
\hline P7ST $_{\text {it }}$ & The total site hit counts of project $i$ in the last 7 days since time $t$ \\
\hline HIST $_{\mathrm{t}}$ & The most site hit counts at time $t$ \\
\hline DEV $_{\text {it }}$ & $\begin{array}{l}\text { Development intensity of project } i \text { at time } j \text {. This variable was defined by SourceForge, which } \\
\text { included CVS commits, history of most recent file released, and the history of administrator } \\
\text { logins. }\end{array}$ \\
\hline P7CT $_{\text {it }}$ & The total CVS commit counts of project $\mathrm{i}$ in the last 7 days since time $t$ \\
\hline HIPT $_{\mathrm{t}}$ & The most CVS-committed counts at time $t$ \\
\hline DALFR $_{\mathrm{it}}$ & $\begin{array}{l}\text { The absolute value of the difference between } 100 \text { and the days (maximally 100) of the latest } \\
\text { file released since time } t\end{array}$ \\
\hline DADML $_{\text {it }}$ & $\begin{array}{l}\text { The absolute value of the difference between } 100 \text { and the days (maximally 100) of last project } \\
\text { administrator login since time } t\end{array}$ \\
\hline
\end{tabular}

Using the above equations, we computed each OSS project's traffic intensity and development intensity at $t_{1}$ and $t_{2}$. The relative ratio between these two at $t_{2}$ and $t_{1}$ was computed for the lag specification. We used the ratio as our dependent variable to investigate the incremental or decremental change across the interval. To avoid missing values resulting from denominators of zero (the intensity at $t_{1}$ may be zero), we added 1 to all values at $t_{1}$. Below are the equations:

$$
\text { traffic_ratio }{ }_{i t 2}=T R F_{i t 2} /_{\left(T R F_{i t 1}+1\right)}
$$




$$
\text { develop_ratio }{ }_{i t 2}=D E V_{i t 2} /\left(D E V_{i t 1}+1\right)
$$

\subsection{Predictors and Control Variables}

We adopted Burt's constraint index (Burt 1992), which measures the extent of the lack of brokerage. The resultant value is a reverse indicator of the number of structural holes. In other words, for any focal OSS project, a high constraint index denotes few structural holes. The equation for Burt's constraint index is presented below.

$$
C_{i}=\sum_{j}\left(P_{i j}+\sum_{q} P_{i q} P_{q j}\right)^{2}, i \neq j \neq q
$$

where $C_{i}$ is Burt's constraint index of vertex $i$ (OSS project $i$ ) and $P_{i j}$ is the proportion of OSS project $i$ 's resources spent on its contact, $j$.

Suppose vertex $i$ has four direct linkages and the strengths of linkage to vertex $j$ and the three other vertexes are 2 and 1 , respectively. Then the value of $P_{i j}$ is $2 / 4$. In our case, the strength of the two projects is measured by the number of common contributors, or administrators or developers. Therefore, we computed Burt's constraint indexes for each OSS project at $\mathrm{T}_{1}$, denoted by admin_citl (administrator-affiliated network) and developer_citl (developer-affiliated network), respectively. To easily obtain the coefficients from the data analysis, we created two proxy variables, $\underline{\boldsymbol{a d m i n}} \boldsymbol{s} \boldsymbol{h}_{i t 1}$ and $\underline{\text { developer }} \boldsymbol{s} \boldsymbol{h}_{i t 1}$, which are computed as 1 minus admin_c $c_{i t 1}$ and developer_c $c_{i t 1}$ (at), to represent the number of structural holes in the administrator-affiliated network and developer-affiliated network, respectively (Tortoriello 2014).

We determined OSS projects' maturity by referring to their developmental phases (i.e., Prealpha, Alpha, Beta, Production, and Mature). Referring to previous studies (Daniel et al. 2013; 
Setia et al. 2012), we categorized the developmental stages into three phases, namely Pre-beta (including Pre-alpha and Alpha), Beta, and Post-beta (Production and Mature). The maturity of an OSS project $i$ at $\mathrm{T}_{1}$ was denoted by a categorical variable, Dev_stage $\boldsymbol{e}_{i t 1}$.

Besides the key predictors, we considered several covariates to control for variance across the affiliation networks and the OSS projects' characteristics. We grouped the control variables into seven main categories: evenness of work distribution, IT-enabled administration, knowledge control, programming language popularity, team-based characteristics, project license, and project category.

Evenness of work distribution: In previous literature, the researchers argued that the uniformity of work distribution among the contributors would have an impact on project success (Woolley et al. 2010). To measure the extent of work distribution, we employed the idea of the Gini coefficient and constructed the generalized inequality indicator for our work (Kuk 2006;

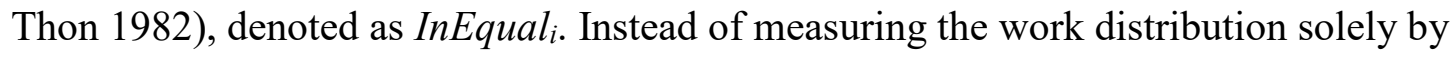
considering the commitment to the OSS project, we acknowledged contributions more comprehensively. In other words, the contribution, like a bug report, features improvement suggestions, and debugging solutions are all included. The equation is as follows:

$$
\text { InEqual }_{i}=\frac{\sum_{j=1}^{n}\left((2 m-n+1) y_{m}\right)}{n^{2} \bar{y}}
$$

where $n$ is the number of contributors to the OSS project $i, y_{m}$ is the count of developer $m$ contributions, and $\bar{y}$ is the average number of contributions expected per contributor.

Notably, the value of $y_{m}, m=1$ to $n$, should be indexed in non-descending order (i.e., $y_{m}<=y_{m+1}$ ). The value of this indicator ranges from 0 to 1 : all contributors performing equal contribution make this indicator approach 0 , and only a few contributors to the focal OSS project 
makes it approach 1 . We employed the aforementioned formula to calculate a variable representing the evenness of work distribution in each OSS project $i$ at $\mathrm{T}_{1}$, denoted by InEqual it $_{\text {. }}$.

IT-enabled administration: SourceForge.net provided several IT artifacts for various purposes, including communication and assistance. In prior literature, researchers have argued that the adoption of IT communication tools can not only increase the efficiency of project teamwork but can also promote quality assurance (Jurison 1999). Accordingly, we checked whether the sampled OSS projects use the available IT tools. In doing so, we included binary variables: use_mail $i_{i t 1}$ to denote whether the e-mail notification was enabled in OSS project $i$ at $\mathrm{T}_{1}$ and $u s e m_{i t 1}$ to denote whether the function of personal messaging was enabled for OSS project $i$ at $\mathrm{T}_{1}$. As depicted previously, whether the focal OSS project enabling the forum is also

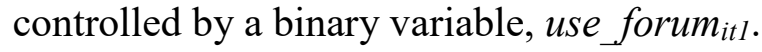

Knowledge control: In addition to the IT tools to support the contributors, several IT artifacts are available to the public from SourceForge.net, from which the end-users can obtain their desired knowledge about the focal OSS project. For instance, (a) users can receive updates on their OSS projects when the Project news function (use_newsi $)$ is enabled; (b) the software screenshots (use_screenshots $_{i}$ ) can provide the users first impressions of the software, which may be extremely important for some software that relies on graphics (e.g., games or multimedia software); and (c) the project wiki (use_wiki $i_{\text {) }}$ provides tutorials or advanced knowledge for endusers and those who may be interested in engaging in further development. All three IT artifacts

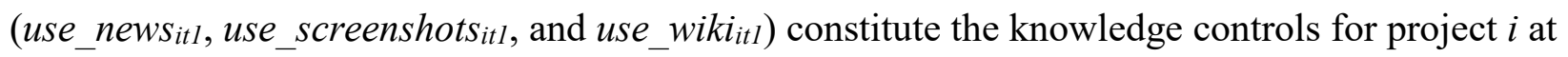
$\mathrm{T}_{1}$.

Programming-Language Popularity: The previous literature demonstrated that programming languages and project types are important considerations in an OSS project (Zhu and Zhou 
2012). For example, more developers may have a minimum knowledge base in popular programming languages such as Java or PHP than in less popular languages. The data set used in this research comprised 79 programming languages; the categorical variable Lang $_{i}$ was used to denote the programming language for OSS project $i$. Also, we referred to the TIOBE Index to control for each language's popularity in OSS project $i$ at $\mathrm{T}_{1}$, (Lang_Popit) because more people are attracted to OSS projects that are written in more popular programming languages. Note that the TIOBE Index is widely recognized for measuring the popularity of programming languages (Paulson 2007), and the higher values refer to higher popularity.

Team-Based Characteristics: Each OSS project is developed and maintained by a group of participants. Therefore, the team-based characteristics may also exert influences on the OSS project's innovation process (Singh et al. 2011a). For instance, the tenure of an OSS project team served as an important representation of the extent of collaborative experiences and relationships (Hahn et al. 2008; Tan et al. 2007); the network size determined the extent to which the miscellaneous information, other than work/project-related information, could flow into the team knowledge base, which could, in turn, affect the innovation output (Hahn et al. 2008; Tan et al. 2007). To this end, we employed two variables, Team_Tenure $e_{i t}$ and Net_Size $e_{i t}$, to indicate the team tenure and network size, respectively, of OSS project $i$ at $T_{1}$. The former was measured as the mean value of team member tenure (by years), and the latter was measured as the number of participants affiliated with a particular OSS project.

OSS License: Various OSS licenses restrain the copyrights, from the permissive licenses (e.g., MIT or BSD) to the protective licenses (e.g., GPL) (Wen et al. 2013). The restriction on the use and distribution of covered software may affect the diffusion of the innovation (e.g., code 
distribution) (Wen et al. 2013). Therefore, we created a categorical control variable, License $_{i}$, indicating the type of license used in a particular OSS project $i$.

Project Category: Our sample included 18 categories of OSS projects. Previous researchers claimed that the nature of OSS projects also affected the innovation output's evolution. For instance, the projects creating applications attracted more end-users than the OSS framework (Dong et al. 2018). Therefore, we created a categorical control variable, Category $y_{i}$, indicating the category of OSS project $i$.

\section{Data Analysis}

\subsection{Main Results}

The unit of analysis is at the OSS-project level. Considering that the dependent variable is a fractional value (i.e., the value is found between 0 and 1), the generalized linear model (GLM) with a canonical logit link in a binomial family is employed (Wooldridge 2010). We constructed two regression models to depict two types of intensity-change ratio, traffic intensity-change ratio, and development intensity-change ratio. The descriptive data analysis and the description of each variable are given in Table 2 . The correlation table is displayed in Table 3 , in which all the coefficients are less than 0.6. We used a variance inflation factor (VIF) to test for multicollinearity. According to the rule of thumb, a VIF value that exceeds five is considered evidence of multicollinearity, and a VIF value that exceeds ten is regarded as serious evidence of multicollinearity. No multicollinearity concerns were found in our models.

\begin{tabular}{|c|c|c|c|c|c|c|c|c|}
\hline \multirow[b]{2}{*}{ Continuous Variables } & \multicolumn{4}{|c|}{$\begin{array}{l}\text { Projects with common administrators } \\
\text { (13305 observations) }\end{array}$} & \multicolumn{4}{|c|}{$\begin{array}{l}\text { Projects with common developers } \\
\text { (12898 observations) }\end{array}$} \\
\hline & Mean. & S.D. & Min. & Max. & Mean. & S.D. & Min. & Max. \\
\hline $\begin{array}{l}\text { Traffic intensity-change ratio of OSS } \\
\text { project } \mathrm{i} \text { at } \mathrm{t}_{2} \text { (traffic_ratio } \text { it } 2_{2} \text { ) }\end{array}$ & 0.093 & 0.077 & 0 & 0.473 & 0.094 & 0.079 & 0 & 0.473 \\
\hline $\begin{array}{l}\text { Development intensity-change ratio } \\
\text { of OSS project } \mathrm{i} \text { at } \mathrm{t}_{2} \\
\left(\text { development_ratio } \text { it } 2_{2}\right)\end{array}$ & 0.329 & 0.118 & 0 & 0.737 & 0.332 & 0.116 & 0 & 0.737 \\
\hline
\end{tabular}




\begin{tabular}{|c|c|c|c|c|c|c|c|c|}
\hline $\begin{array}{l}\text { Number of structural holes in } \\
\text { common administrator network of } \\
\text { project } \mathrm{i} \text { at } \mathrm{t}_{1}\left(\text { admin_sh } h_{\text {itt }}\right)\end{array}$ & 0.280 & 0.272 & 0 & 0.937 & -- & -- & -- & -- \\
\hline $\begin{array}{l}\text { Number of structural holes in } \\
\text { common developer network of } \\
\text { project i at } \mathrm{t}_{1} \text { (developer } s h_{i t 1} \text { ) }\end{array}$ & -- & -- & -- & -- & 0.285 & 0.276 & 0 & 0.975 \\
\hline $\begin{array}{l}\text { Generalized inequality indicator of } \\
\text { work distribution between all } \\
\text { contributors at } \mathrm{t}_{1}\left(\operatorname{InEqul}_{\mathrm{itl}}\right)\end{array}$ & 0.437 & 0.143 & 0 & 0.954 & 0.442 & 0.145 & 0 & 0.956 \\
\hline $\begin{array}{l}\text { Popularity of programming language } \\
(\text { Lang_Pop } i t 1)\end{array}$ & 0.117 & 0.068 & 0.0001 & 0.205 & 0.117 & 0.067 & 0.0001 & 0.205 \\
\hline $\begin{array}{l}\text { Team tenure }\left(\text { Team_Tenure }_{i t}\right) \text {, in } \\
\text { years }\end{array}$ & 5.871 & 2.330 & 0.003 & 9.6 & 5.961 & 2.330 & 0.003 & 9.6 \\
\hline Team network size (Net_Size $i t 1)$ & 3.152 & 7.336 & 1 & 430 & 3.289 & 7.678 & 1 & 430 \\
\hline \multicolumn{9}{|l|}{ Categorical Variables } \\
\hline \multicolumn{9}{|l|}{ Developmental Stages (Dev stage $\left._{i t t}\right)$} \\
\hline Dev stage $_{i t l}=0$ (Pre-beta phase) & \multicolumn{4}{|l|}{7,915} & \multicolumn{4}{|l|}{7,542} \\
\hline Dev stage $_{i t l}=1$ (beta phase) & \multicolumn{4}{|l|}{2,088} & \multicolumn{4}{|l|}{2,061} \\
\hline Dev stage $_{i t l}=2$ (Post-beta phase) & \multicolumn{4}{|l|}{3,302} & \multicolumn{4}{|l|}{3,295} \\
\hline \multicolumn{9}{|c|}{ Whether project $i$ enables email function $\left(\right.$ use mail $_{i}$ ) } \\
\hline $\begin{array}{l}\text { use_mail }{ }_{i}=0 \text { (Disabled email } \\
\text { function) }\end{array}$ & \multicolumn{4}{|c|}{2,026} & \multicolumn{4}{|l|}{1,935} \\
\hline use_mail ${ }_{i}=1$ (Enabled email function) & \multicolumn{4}{|l|}{11,279} & \multicolumn{4}{|l|}{10,963} \\
\hline \multicolumn{9}{|c|}{ Whether project $i$ enables internal messages function $\left(u s e \quad p m_{i}\right)$} \\
\hline $\begin{array}{l}\text { use } p_{i}=0 \text { (Disabled internal } \\
\text { message function) }\end{array}$ & \multicolumn{4}{|l|}{2,546} & \multicolumn{4}{|l|}{2,479} \\
\hline $\begin{array}{l}\text { use_pm }=1 \text { (Enabled internal } \\
\text { message function) }\end{array}$ & \multicolumn{4}{|l|}{10,759} & \multicolumn{4}{|l|}{10,419} \\
\hline \multicolumn{9}{|c|}{ Whether project $i$ enables forum function $($ use forum $i)$} \\
\hline $\begin{array}{l}\text { use_forum }{ }_{i}=0 \text { (Disabled forum } \\
\text { function) }\end{array}$ & \multicolumn{4}{|l|}{2,766} & \multicolumn{4}{|l|}{2,692} \\
\hline $\begin{array}{l}\text { use forum }{ }_{i}=1 \text { (Enabled forum } \\
\text { function) }\end{array}$ & \multicolumn{4}{|l|}{10,539} & \multicolumn{4}{|l|}{10,206} \\
\hline \multicolumn{9}{|c|}{ Whether project $i$ uses newsletters $($ use news $i)$} \\
\hline $\begin{array}{l}\text { use_news } s_{i}=0 \text { (Disabled newsletters } \\
\text { function) }\end{array}$ & \multicolumn{4}{|l|}{926} & \multicolumn{4}{|l|}{901} \\
\hline $\begin{array}{l}\text { use_news }=1 \text { (Enabled newsletters } \\
\text { function) }\end{array}$ & \multicolumn{4}{|l|}{12,379} & \multicolumn{4}{|l|}{11,997} \\
\hline \multicolumn{9}{|c|}{ Whether project $i$ uses screenshots (use screenshots $\left._{i}\right)$} \\
\hline $\begin{array}{l}\text { use_screenshots }{ }_{i}=0 \text { (Disabled } \\
\text { screenshots function) }\end{array}$ & \multicolumn{4}{|l|}{911} & 859 & & & \\
\hline $\begin{array}{l}\text { use_screenshots }=1 \text { (Enabled } \\
\text { screenshots function) }\end{array}$ & 12,394 & & & & 12,039 & & & \\
\hline Whether project $i$ uses project wiki $(u s$ & wiki & & & & & & & \\
\hline use wiki $i_{i}=$ (Disabled project wiki) & 12,162 & & & & 11,775 & & & \\
\hline use wiki $_{i}=1$ (Enabled project wiki) & 1,143 & & & & 1,123 & & & \\
\hline
\end{tabular}

Programming languages (Lang $)$ ): 79 programming languages were considered (Java, PHP, Python, C\#, C++, C,

Visual Basic, ASP.NET, Perl, Assembly, Lisp, XSL (XSLT/XPath/XSL-FO), Visual Basic .NET, JavaScript, Unix Shell, Fortran, S/R, ActionScript, AppleScript, BASIC, Pascal, Tcl, AspectJ, Prolog, Objective C, Ruby, Object Pascal, Euphoria, Standard ML, Oberon, Smalltalk, PL/SQL, MATLAB, OCaml (Objective Caml), Free Pascal, ASP, Logo, Delphi/Kylix, APL, IDL, JSP, D, Erlang, Lazarus, XBase/Clipper, VBScript, Visual FoxPro, Emacs-Lisp, MUMPS, Flex, Scheme, Ada, Groovy, COBOL, Lua, Forth, Mathematica, Eiffel, REALbasic, XBasic, haXe, Haskell, Curl, AWK, Kaya, Visual Basic for Applications (VBA), Modula, Clean, LPC, Rexx, Common Lisp, LabVIEW, VHDL/Verilog, PROGRESS, Pike, Cold Fusion, Boo, Oz, other).

OSS licenses (License ${ }_{i}$ ): 56 OSS licenses were considered (apache, gpl, lgpl, apache2, python, bsd, website, artistic, zlib, publicdomain, mit, public, ibmcpl, nethack, educom, afl, apsl, eclipselicense, wxwindows, $\mathrm{mpl}$, cddl, psfl, 
sleepycat, ibm, osl, mpl11, qpl, zope, adaptive, none, sissl, php-license, fair, gplv3, w3c, boostlicense, cpal, rpl15, ncsa, historical, php, attribut, agpl, iosl, sunpublic, real, opengroup, osi, ms-rl, datagrid, eiffel, jabber, eiffel2, rscpl, rpl, other).

OSS project categories (Category ): 18 categories were considered (development, games, Internet, scientific, system, education, desktop, communications, security, editors, multimedia, formats_and_protocols, database, office, printing, religion, mobileapps, other). 


\begin{tabular}{|c|c|c|c|c|c|c|c|c|c|c|c|c|}
\hline & $a d m i n \_s h_{i t}$ & InEqul $l_{i t 1}$ & $\underset{t 1}{\text { Lang_Pop }_{i}}$ & $\begin{array}{l}\text { use_mai } \\
l_{i}\end{array}$ & $\begin{array}{l}\text { use } p \\
m_{i}\end{array}$ & $\begin{array}{l}\text { use foru } \\
m_{i}\end{array}$ & $\begin{array}{l}\text { use_new } \\
s_{i}\end{array}$ & $\begin{array}{l}\text { use_screensho } \\
t_{i}\end{array}$ & $\begin{array}{l}\text { use_wik } \\
i_{i}\end{array}$ & $\begin{array}{l}\text { Team_Tenure } \\
\text { it } 1\end{array}$ & $\begin{array}{l}\text { Net_Siz } \\
e_{i t 1}\end{array}$ & VIFs \\
\hline admin_sh $h_{i t 1}$ & 1 & & & & & & & & & & & 1.04 \\
\hline InEqul $_{i t 1}$ & 0.146 & 1 & & & & & & & & & & 1.48 \\
\hline Lang_Pop ${ }_{i t I}$ & 0.008 & 0.001 & 1 & & & & & & & & & 1.00 \\
\hline use_mail $_{i}$ & -0.023 & 0.030 & 0.023 & 1 & & & & & & & & 1.44 \\
\hline use_pmi & -0.074 & -0.062 & -0.003 & 0.505 & 1 & & & & & & & 1.81 \\
\hline use forum $_{i}$ & -0.105 & -0.089 & 0.0002 & 0.434 & 0.552 & 1 & & & & & & 1.61 \\
\hline use_news & -0.066 & -0.021 & -0.001 & 0.316 & 0.396 & 0.378 & 1 & & & & & 1.27 \\
\hline $\begin{array}{l}\text { use_screensho } \\
t s_{i}\end{array}$ & -0.036 & -0.043 & -0.008 & 0.243 & 0.369 & 0.216 & 0.216 & 1 & & & & 1.20 \\
\hline use_wiki $i_{i}$ & -0.004 & 0.015 & -0.026 & 0.049 & 0.057 & 0.066 & 0.022 & 0.022 & 1 & & & 1.06 \\
\hline Team_Tenure $_{i t}$ & 0.134 & 0.0387 & 0.030 & -0.093 & -0.122 & -0.142 & -0.135 & -0.012 & -0.179 & 1 & & 1.08 \\
\hline Net_Size $e_{i t 1}$ & 0.144 & 0.233 & 0.014 & 0.012 & -0.107 & -0.153 & -0.042 & -0.087 & 0.037 & -0.013 & 1 & 1.10 \\
\hline \multicolumn{13}{|c|}{ Projects with common developers } \\
\hline & $\begin{array}{l}\text { developer } \\
s h_{i t 1}\end{array}$ & $\operatorname{InEqul}_{i t 1}$ & ${ }_{t 1}^{\text {Lang_Pop }}{ }_{t}$ & $\begin{array}{l}\text { use_mai } \\
l_{i}\end{array}$ & $\begin{array}{l}\text { use } p \\
m_{i}\end{array}$ & $\begin{array}{l}\text { use foru } \\
m_{i}\end{array}$ & $\begin{array}{l}\text { use_new } \\
s_{i}\end{array}$ & $\begin{array}{l}\text { use_screensho } \\
t s_{i}\end{array}$ & $\begin{array}{l}\text { use_wik } \\
i_{i}\end{array}$ & $\begin{array}{l}\text { Team_Tenure } \\
\text { itl }\end{array}$ & $\begin{array}{l}\text { Net_Siz } \\
e_{i t 1}\end{array}$ & \\
\hline developer_sh $h_{i t 1}$ & 1 & & & & & & & & & & & 1.07 \\
\hline $\operatorname{InEqul_{it1}}$ & 0.196 & 1 & & & & & & & & & & 1.48 \\
\hline Lang_Pop ${ }_{i t 1}$ & 0.005 & -0.001 & 1 & & & & & & & & & 1.00 \\
\hline use_mail ${ }_{i}$ & -0.021 & 0.033 & 0.028 & 1 & & & & & & & & 1.42 \\
\hline use $p_{i}$ & -0.076 & -0.059 & -0.001 & 0.495 & 1 & & & & & & & 1.80 \\
\hline use forum $_{i}$ & -0.076 & -0.0940 & -0.0002 & 0.431 & 0.547 & 1 & & & & & & 1.61 \\
\hline use_news & -0.065 & -0.022 & -0.005 & 0.299 & 0.403 & 0.378 & 1 & & & & & 1.27 \\
\hline $\begin{array}{l}\text { use_screensho } \\
t_{i}\end{array}$ & -0.035 & -0.034 & -0.012 & 0.236 & 0.360 & 0.274 & 0.211 & 1 & & & & 1.19 \\
\hline use_wiki & 0.002 & 0.018 & -0.024 & 0.050 & 0.055 & 0.045 & 0.066 & 0.017 & 1 & & & 1.06 \\
\hline Team_Tenure $_{i t}$ & 0.158 & 0.045 & 0.028 & -0.092 & -0.122 & -0.145 & -0.14 & -0.01 & -0.182 & 1 & & 1.09 \\
\hline Net_Size ${ }_{i t 1}$ & 0.194 & 0.256 & 0.012 & 0.017 & -0.113 & -0.151 & -0.045 & -0.078 & 0.046 & -0.006 & 1 & 1.13 \\
\hline
\end{tabular}


The findings depicting the change in traffic intensity are summarized in Table $4^{9}$. Model 1 is the base model with traffic_ratio it $2_{2}$ as the dependent variable, in which only the control variables are included. In Model 2, the number of structural holes computed from the affiliated network with common administrators was entered to test Hypothesis 1a. The significantly positive coefficient of admin_sh $h_{i t}$ supports Hypothesis 1a. In Model 3, the number of structural holes (developer_sh $\left.h_{i t 1}\right)$ in the network constructed with interconnected developers was positively significant. Hence, Hypothesis $\mathbf{1 b}$ is also supported.

To test the moderating effect in Hypothesis 3, the maturity, Dev_stage $i t$, and the interaction terms, admin_sh $h_{i t 1} X D e v \_s t a g e_{i t 1}$ and developer_sh $h_{i t 1} X D e v \_s t a g e_{i t 1}$, are entered into Model 4 through Model 7. We first tested the moderating effect between maturity and the number of structural holes computed from the affiliated network with common administrators in Model 4 and Model 5. In Model 4, we set the OSS projects at a pre-beta phase as the base to investigate whether the positive relationship between the number of structural holes and the traffic intensity is strengthened in beta projects but not post-beta projects, partially supporting our hypothesis. In Model 5, we changed the base group from the pre-beta phase to the beta phase to test the difference in the moderating effect of beta and post-beta projects. The estimated coefficient is negatively significant in the post-beta phase. Similarly, we conducted the same empirical testing for the affiliated network with common developers in Model 6 and Model 7 and obtained similar results. Therefore, we can conclude that Hypothesis 3 is partially supported.

\footnotetext{
${ }^{9}$ We did not include the admin_sh ${ }_{\text {it1 }}$ and developer_sh ${ }_{\text {it1 }}$ in the same model because of the multicollinearity. These two independent variables are highly correlated.
} 


\begin{tabular}{|c|c|c|c|c|c|c|c|}
\hline \multirow[t]{2}{*}{ DV } & \multicolumn{7}{|c|}{ Traffic intensity-change ratio (traffic_ratio it $_{2}$ ) } \\
\hline & Model 1 & Model 2 & Model 3 & Model 4 & Model 5 & Model 6 & Model 7 \\
\hline admin_sh $h_{i t 1}$ & -- & $\begin{array}{l}0.114 * * * \\
(0.031)\end{array}$ & -- & $\begin{array}{l}0.077^{*} \\
(0.039) \\
\end{array}$ & $\begin{array}{l}0.287 * * * \\
(0.063)\end{array}$ & -- & -- \\
\hline developer_shitI & -- & -- & $\begin{array}{l}0.149 * * * \\
(0.035)\end{array}$ & -- & -- & $\begin{array}{l}0.077+ \\
(0.041)\end{array}$ & $\begin{array}{l}0.282 * * * \\
(0.063)\end{array}$ \\
\hline Dev_stage $_{i t 1}<$ Beta & -- & -- & -- & -- & $\begin{array}{l}-0.26 * * * \\
(0.032)\end{array}$ & -- & $\begin{array}{l}-0.261 * * * \\
(0.032)\end{array}$ \\
\hline Dev_stage $i t 1=$ Beta & -- & -- & -- & $\begin{array}{l}0.26^{* * * *} \\
(0.032)\end{array}$ & -- & $\begin{array}{l}0.261 * * * \\
(0.032)\end{array}$ & -- \\
\hline Dev_stage $_{i t 1}>$ Beta & -- & -- & -- & $\begin{array}{l}0.496 * * * \\
(0.027) \\
\end{array}$ & $\begin{array}{l}0.236^{* * *} \\
(0.032) \\
\end{array}$ & $\begin{array}{l}0.468 * * * \\
(0.027)\end{array}$ & $\begin{array}{l}0.207 * * * \\
(0.033)\end{array}$ \\
\hline $\begin{array}{l}\text { admin_sh } i t 1 X D e v \_s t a g e_{i t 1}< \\
\text { Beta }\end{array}$ & -- & -- & -- & -- & $\begin{array}{l}-0.21^{* *} \\
(0.072) \\
\end{array}$ & -- & -- \\
\hline $\begin{array}{l}\text { admin_sh } i t 1 X D e v \_s t a g e e_{i t 1}= \\
\text { Beta }\end{array}$ & -- & -- & -- & $\begin{array}{l}0.21 * * \\
(0.072)\end{array}$ & -- & -- & -- \\
\hline $\begin{array}{l}\text { admin_sh } i t 1 X D e v \_s t a g e_{i t 1}> \\
\text { Beta }\end{array}$ & -- & -- & -- & $\begin{array}{l}0.013 \\
(0.061) \\
\end{array}$ & $\begin{array}{l}-0.198 * * \\
(0.076) \\
\end{array}$ & -- & -- \\
\hline $\begin{array}{l}\text { developer_sh } h_{i t} X D e v \_s t a g e_{i t 1}< \\
\text { Beta }\end{array}$ & -- & -- & -- & -- & -- & -- & $\begin{array}{l}-0.205^{* *} \\
(0.072) \\
\end{array}$ \\
\hline $\begin{array}{l}\text { developer_sh } h_{i t} X D e v \_s t a g e_{i t l}= \\
\text { Beta }\end{array}$ & -- & -- & -- & -- & -- & $\begin{array}{l}0.205 * * \\
(0.072)\end{array}$ & -- \\
\hline $\begin{array}{l}\text { developer_shitlXDev_stage } e_{i t}> \\
\text { Beta }\end{array}$ & -- & -- & -- & -- & -- & $\begin{array}{l}0.071 \\
(0.062)\end{array}$ & $\begin{array}{l}-0.134+ \\
(0.076) \\
\end{array}$ \\
\hline InEqul $l_{i t 1}$ & $\begin{array}{l}0.932 * * * \\
(0.082)\end{array}$ & $\begin{array}{l}0.796 * * * \\
(0.09)\end{array}$ & $\begin{array}{l}0.868 * * * \\
(0.089)\end{array}$ & $\begin{array}{l}0.644 * * * \\
(0.076)\end{array}$ & $\begin{array}{l}0.644 * * * \\
(0.076)\end{array}$ & $\begin{array}{l}0.707 * * * \\
(0.077)\end{array}$ & $\begin{array}{l}0.707 * * * \\
(0.077)\end{array}$ \\
\hline use_mailit & $\begin{array}{l}0.158 * * * \\
(0.026)\end{array}$ & $\begin{array}{l}0.152 * * * \\
(0.027)\end{array}$ & $\begin{array}{l}0.149 * * * \\
(0.027)\end{array}$ & $\begin{array}{l}0.143 * * * \\
(0.026)\end{array}$ & $\begin{array}{l}0.143 * * * \\
(0.026)\end{array}$ & $\begin{array}{l}0.144 * * * \\
(0.027)\end{array}$ & $\begin{array}{l}0.144 * * * \\
(0.027)\end{array}$ \\
\hline use_pmitl & $\begin{array}{l}-0.269^{* * * *} \\
(0.024)\end{array}$ & $\begin{array}{l}-0.281^{* * * *} \\
(0.025)\end{array}$ & $\begin{array}{l}-0.263 * * * \\
(0.025)\end{array}$ & $\begin{array}{l}-0.244 * * * \\
(0.024)\end{array}$ & $\begin{array}{l}-0.244 * * * \\
(0.024)\end{array}$ & $\begin{array}{l}-0.229 * * * \\
(0.024)\end{array}$ & $\begin{array}{l}-0.229^{* * *} \\
(0.024)\end{array}$ \\
\hline use forum $_{\text {itl }}$ & $\begin{array}{l}-0.186^{* * *} \\
(0.023)\end{array}$ & $\begin{array}{l}-0.178^{* * *} \\
(0.026)\end{array}$ & $\begin{array}{l}-0.176^{* * * *} \\
(0.024)\end{array}$ & $\begin{array}{l}-0.167^{* * *} \\
(0.024)\end{array}$ & $\begin{array}{l}-0.167 * * * \\
(0.024)\end{array}$ & $\begin{array}{l}-0.164 * * * \\
(0.023)\end{array}$ & $\begin{array}{l}-0.164^{* * *} \\
(0.023)\end{array}$ \\
\hline use_newsitl & $\begin{array}{l}0.119 * * * \\
(0.031)\end{array}$ & $\begin{array}{l}0.127 * * * \\
(0.034)\end{array}$ & $\begin{array}{l}0.107 * * \\
(0.034) \\
\end{array}$ & $\begin{array}{l}0.148^{* * *} \\
(0.033)\end{array}$ & $\begin{array}{l}0.148 * * * \\
(0.033) \\
\end{array}$ & $\begin{array}{l}0.124 * * * \\
(0.033)\end{array}$ & $\begin{array}{l}0.124 * * * \\
(0.033) \\
\end{array}$ \\
\hline use_screenshotsitl & $\begin{array}{l}-0.134 * * * \\
(0.029)\end{array}$ & $\begin{array}{l}-0.118^{* * *} \\
(0.032)\end{array}$ & $\begin{array}{l}-0.116^{* * *} \\
(0.031)\end{array}$ & $\begin{array}{l}-0.132 * * * \\
(0.031) \\
\end{array}$ & $\begin{array}{l}-0.132^{* * *} \\
(0.031)\end{array}$ & $\begin{array}{l}-0.124 * * * \\
(0.031)\end{array}$ & $\begin{array}{l}-0.124 * * * \\
(0.031)\end{array}$ \\
\hline use_wiki itl & $\begin{array}{l}0.146^{* * *} \\
(0.026)\end{array}$ & $\begin{array}{l}0.134 * * * \\
(0.029)\end{array}$ & $\begin{array}{l}0.138 * * * \\
(0.028)\end{array}$ & $\begin{array}{l}0.194 * * * \\
(0.028)\end{array}$ & $\begin{array}{l}0.194 * * * \\
(0.028)\end{array}$ & $\begin{array}{l}0.196 * * * \\
(0.027)\end{array}$ & $\begin{array}{l}0.196 * * * \\
(0.027)\end{array}$ \\
\hline Lang_Popit1 & $\begin{array}{l}-206.83 * * \\
(65.338) \\
\end{array}$ & $\begin{array}{l}-199.277^{*} \\
(85.514) \\
\end{array}$ & $\begin{array}{l} \\
206.954 * * \\
(76.792) \\
\end{array}$ & $\begin{array}{l}-170.758^{*} \\
(73.066) \\
\end{array}$ & $\begin{array}{l}-170.758^{*} \\
(73.066) \\
\end{array}$ & $\begin{array}{l}- \\
182.183^{* *} \\
(67.321) \\
\end{array}$ & $\begin{array}{l}- \\
182.183 * * \\
(67.321) \\
\end{array}$ \\
\hline Team_Tenure $_{i t 1}$ & $\begin{array}{l}0.021 * * * \\
(0.003)\end{array}$ & $\begin{array}{l}0.02 * * * \\
(0.004) \\
\end{array}$ & $\begin{array}{l}0.021 * * * \\
(0.004)\end{array}$ & $\begin{array}{l}-0.012 * * \\
(0.004) \\
\end{array}$ & $\begin{array}{l}-0.012 * * \\
(0.004) \\
\end{array}$ & $\begin{array}{l}-0.011^{*} \\
(0.004)\end{array}$ & $\begin{array}{l}-0.011^{*} \\
(0.004)\end{array}$ \\
\hline Net_Size $i t 1$ & $\begin{array}{l}0.015 * * * \\
(0.004)\end{array}$ & $\begin{array}{l}0.015 * * * \\
(0.005)\end{array}$ & $\begin{array}{l}0.015 * * * \\
(0.004)\end{array}$ & $\begin{array}{l}0.011^{* *} \\
(0.004) \\
\end{array}$ & $\begin{array}{l}0.011 * * \\
(0.004) \\
\end{array}$ & $\begin{array}{l}0.011 \text { ** } \\
(0.004) \\
\end{array}$ & $\begin{array}{l}0.011 * * \\
(0.004) \\
\end{array}$ \\
\hline constant & $\begin{array}{l}-3.319^{* * * *} \\
(0.191)\end{array}$ & $\begin{array}{l}-3.28 * * * \\
(0.193) \\
\end{array}$ & $\begin{array}{l}-3.383 * * * \\
(0.199)\end{array}$ & $\begin{array}{l}-3.125^{* * *} \\
(0.187)\end{array}$ & $\begin{array}{l}-2.864 * * * \\
(0.189)\end{array}$ & $\begin{array}{l}-3.211^{* * *} \\
(0.193)\end{array}$ & $\begin{array}{l}-2.95 * * * \\
(0.195) \\
\end{array}$ \\
\hline \multicolumn{8}{|c|}{ Lang $_{i}$, License $_{i}$, Category $:$ Included but not reported } \\
\hline Log-pseudo likelihood & -3337.346 & -3018.902 & -2949.184 & -2998.722 & -2998.722 & -2930.249 & -2930.249 \\
\hline
\end{tabular}


In Table 5, the dependent variable was replaced with development_ratio ${ }_{i t 2}$, which is the development intensity-change ratio, to test Hypotheses $2 \mathrm{a}, 2 \mathrm{~b}$, and 4 . The estimated coefficients are listed from Model 8 to Model 14. In a similar vein, Model 8 is the base model, which only includes the control variables. The number of structural holes from the administrator-affiliated network was entered in Model 9. The results table shows that the $a d m i n \_s h_{i t l}$ has significant negative effects on the change in development intensity. Therefore, Hypothesis 2a is supported. In Model 10, the estimated coefficient of developer_sh $h_{i t}$ is found to be significantly negative, as well, which supports Hypothesis $2 \mathbf{b}$.

The maturity, Dev_stage $i t 1$, and the interaction terms, admin_sh $h_{i t 1} X D e v \_s t a g e_{i t 1}$ and developer_sh $h_{i t 1} X D e v \_s t a g e_{i t 1}$, are entered from Model 11 to Model 14. Interestingly, the estimated coefficients of the interaction terms are insignificant in administrator-affiliated and developer-affiliated networks regardless of the base group. Therefore, we conclude that Hypothesis 4 is not supported.

Overall, the results indicate that OSS projects with a greater number of structural holes can enjoy higher popularity in administrator-affiliated networks (the p-value of the coefficient [0.114] of admin_sh $h_{i t 1}$ less than 0.001) and developer-affiliated networks (the p-value of the coefficient [0.149] of developer_sh $h_{i t 1}$ is less than 0.001). However, OSS projects with a greater number of structural holes suffer from less knowledge creation in the administrator-affiliated network (coefficient $\left[a d m i n \_s h_{i t 1}\right]=-0.175, \mathrm{p}$-value $\left.<0.001\right)$ and developer-affiliated network (coefficient [developer_sh $\left.h_{i t 1}\right]=-0.170, \mathrm{p}$-value $\left.<0.001\right)$. This finding implies the OSS project that is tightly connected with the others is more likely to intensify the innovation development by contributors. Also, the OSS project's maturity is found to strengthen the positive relationship between the number of structural holes and traffic intensity in administrator-affiliated and 
developer-affiliated networks. However, such a positive moderating effect can only be observed between pre-beta and beta OSS projects. No significant difference emerged in the moderating effect between projects in the pre-beta phase and those in the post-beta phase. This interesting finding indicates the externally accessed information could be most effectively assimilated to popularize the innovation when the OSS project was in the beta phase. Such a conclusion is not counterintuitive. In the software release life cycle, the beta version was used to gather feedback on bugs or possible new features (MacCormack 2001). Therefore, more information ought to intensely flow into those OSS projects through the connected network in the beta phase. Last, project maturity was not found to enhance the negative relationship between the number of structural holes and development intensity. To further validate our empirical findings, we plotted the estimations in Figure 1 below. Figures 1(a) and 1(b) show the results estimated in Table 4, where the gradient of the red line (beta phase) was steeper than those of the other two lines. The blue line (pre-beta phase) was almost parallel to the green line (post-beta phase), implying the positive moderation effect between the beta phase and the two other phases. In addition, all three lines were almost parallel to each other in Figures 1(c) and 1(d). 


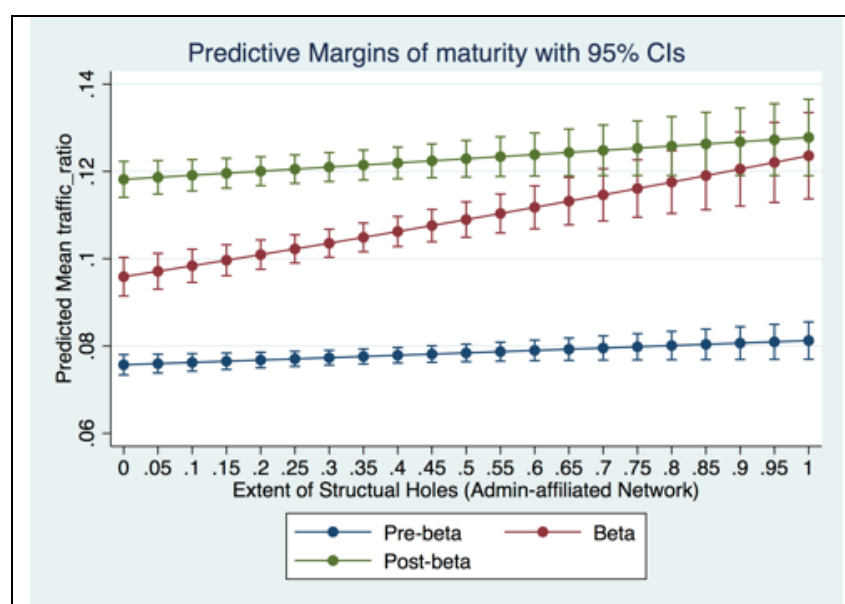

(a)

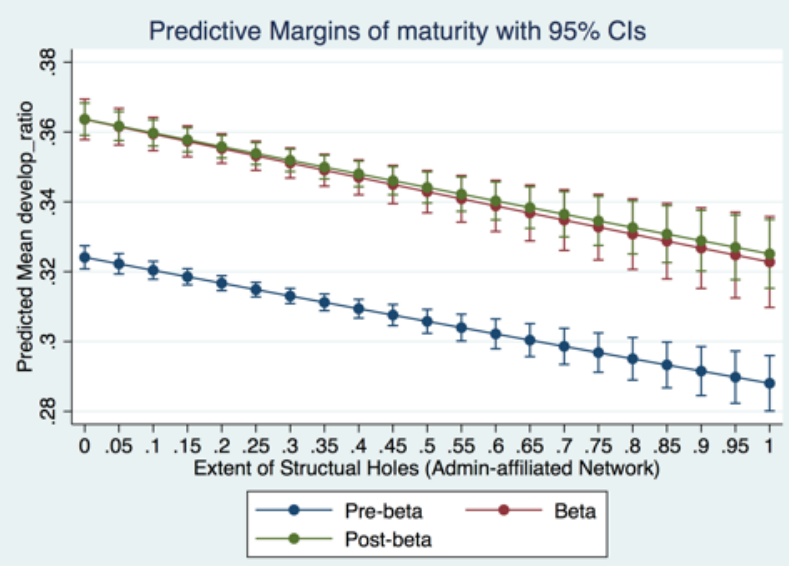

(c)

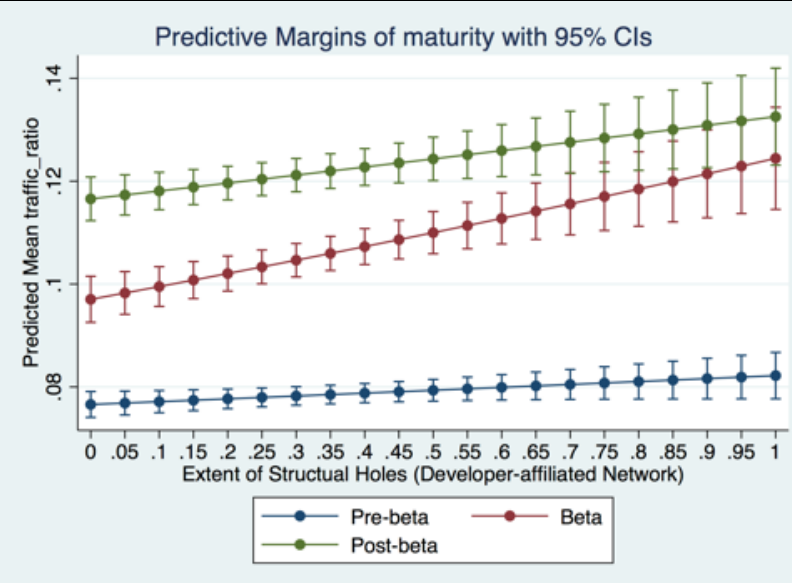

(b)

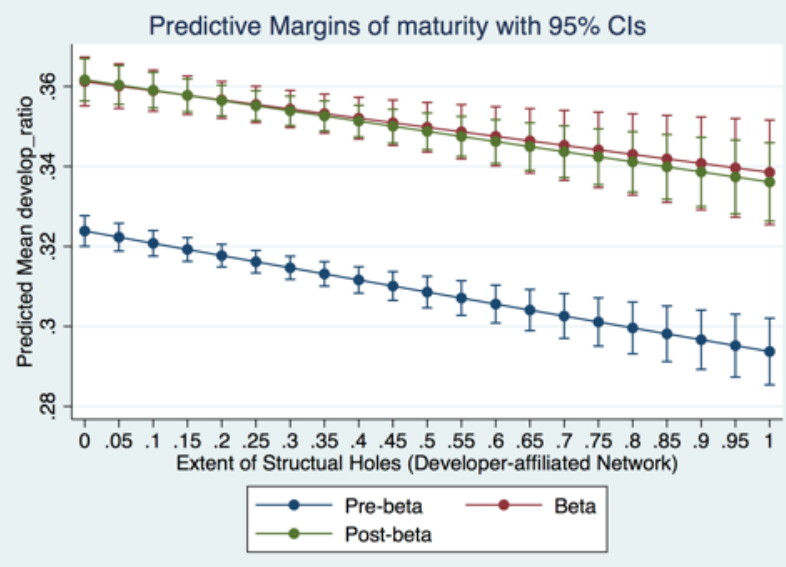

(d) 


\begin{tabular}{|c|c|c|c|c|c|c|c|}
\hline \multirow[t]{2}{*}{ DV } & \multicolumn{7}{|c|}{ Development intensity change ratio (development_ratio ${ }_{i t 2}$ ) } \\
\hline & Model 8 & Model 9 & Model 10 & Model 11 & Model 12 & Model 13 & Model 14 \\
\hline admin_sh ${ }_{i t l}$ & -- & $\begin{array}{l}-0.175^{* * *} \\
(0.018)\end{array}$ & -- & $\begin{array}{l}-0.170 * * * \\
(0.025)\end{array}$ & $\begin{array}{l}-0.182 * * * \\
(0.038)\end{array}$ & -- & -- \\
\hline developer_shitl & -- & -- & $\begin{array}{l}-0.125^{* * *} \\
(0.018)\end{array}$ & -- & -- & $\begin{array}{l}-0.142^{* * *} \\
(0.025)\end{array}$ & $\begin{array}{l}-0.100 * * \\
(0.037)\end{array}$ \\
\hline Dev_stage $e_{i t 1}<$ Beta & -- & -- & -- & -- & $\begin{array}{l}-0.176^{* * * *} \\
(0.017) \\
\end{array}$ & -- & $\begin{array}{l}-0.166^{* * *} \\
(0.017)\end{array}$ \\
\hline Dev_stageitl $=$ Beta & -- & -- & -- & $\begin{array}{l}0.176^{* * *} \\
(0.017)\end{array}$ & -- & $\begin{array}{l}0.166^{* * *} \\
(0.017) \\
\end{array}$ & -- \\
\hline Dev_stage $e_{i t 1}>$ Beta & -- & -- & -- & $\begin{array}{l}0.176^{* * *} \\
(0.015)\end{array}$ & $\begin{array}{l}0.0003 \\
(0.017)\end{array}$ & $\begin{array}{l}0.168 * * * \\
(0.015)\end{array}$ & $\begin{array}{l}0.002 \\
(0.017)\end{array}$ \\
\hline $\begin{array}{l}\text { admin_sh }{ }_{i t l} X D e v \_s t a g e_{i t 1}< \\
\text { Beta }\end{array}$ & -- & -- & -- & -- & $\begin{array}{l}0.011 \\
(0.045)\end{array}$ & -- & -- \\
\hline $\begin{array}{l}\text { admin_shitlXDev_stage } i t 1= \\
\text { Beta }\end{array}$ & -- & -- & -- & $\begin{array}{l}-0.011 \\
(0.045)\end{array}$ & -- & -- & -- \\
\hline $\begin{array}{l}\text { admin_sh } i t 1 X D e v \_s t a g e_{i t 1}> \\
\text { Beta }\end{array}$ & -- & -- & -- & $\begin{array}{l}-0.001 \\
(0.038)\end{array}$ & $\begin{array}{l}0.01 \\
(0.047)\end{array}$ & -- & -- \\
\hline $\begin{array}{l}\text { developer_shitlXDev_stageit } \\
1<\text { Beta }\end{array}$ & -- & -- & -- & -- & -- & -- & $\begin{array}{l}-0.041 \\
(0.044)\end{array}$ \\
\hline $\begin{array}{l}\text { developer_shitlXDev_stageit } \\
l=\text { Beta }\end{array}$ & -- & -- & -- & -- & -- & $\begin{array}{l}0.041 \\
(0.044)\end{array}$ & -- \\
\hline $\begin{array}{l}\text { developer_shitlXDev_stageit } \\
1>\text { Beta }\end{array}$ & -- & -- & -- & -- & -- & $\begin{array}{l}0.029 \\
(0.038)\end{array}$ & $\begin{array}{l}-0.013 \\
(0.046)\end{array}$ \\
\hline InEqul ${ }_{i t 1}$ & $\begin{array}{l}-0.128^{* * *} \\
(0.031) \\
\end{array}$ & $\begin{array}{l}-0.117^{* * *} \\
(0.032) \\
\end{array}$ & $\begin{array}{l}-0.098 * * \\
(0.032) \\
\end{array}$ & $\begin{array}{l}-0.15 * * * \\
(0.032) \\
\end{array}$ & $\begin{array}{l}-0.15 * * * \\
(0.032) \\
\end{array}$ & $\begin{array}{l}-0.136^{* * *} \\
(0.033) \\
\end{array}$ & $\begin{array}{l}-0.136^{* * *} \\
(0.033) \\
\end{array}$ \\
\hline use_mail $l_{i t 1}$ & $\begin{array}{l}-0.036^{*} \\
(0.015) \\
\end{array}$ & $\begin{array}{l}-0.036^{*} \\
(0.016) \\
\end{array}$ & $\begin{array}{l}-0.038^{*} \\
(0.015) \\
\end{array}$ & $\begin{array}{l}-0.037^{*} \\
(0.016) \\
\end{array}$ & $\begin{array}{l}-0.037^{*} \\
(0.016) \\
\end{array}$ & $\begin{array}{l}-0.038^{*} \\
(0.015) \\
\end{array}$ & $\begin{array}{l}-0.038^{*} \\
(0.015) \\
\end{array}$ \\
\hline use_pmitl & $\begin{array}{l}-0.023 \\
(0.015) \\
\end{array}$ & $\begin{array}{l}-0.028+ \\
(0.016) \\
\end{array}$ & $\begin{array}{l}-0.019 \\
(0.016)\end{array}$ & $\begin{array}{l}-0.017 \\
(0.016) \\
\end{array}$ & $\begin{array}{l}-0.017 \\
(0.016)\end{array}$ & $\begin{array}{l}-0.01 \\
(0.016)\end{array}$ & $\begin{array}{l}-0.01 \\
(0.016)\end{array}$ \\
\hline use_forum ${ }_{i t 1}$ & $\begin{array}{l}0.003 \\
(0.014)\end{array}$ & $\begin{array}{l}-0.00002 \\
(0.015)\end{array}$ & $\begin{array}{l}0.002 \\
(0.015)\end{array}$ & $\begin{array}{l}0.003 \\
(0.015)\end{array}$ & $\begin{array}{l}0.003 \\
(0.015)\end{array}$ & $\begin{array}{l}0.005 \\
(0.015) \\
\end{array}$ & $\begin{array}{l}0.005 \\
(0.015) \\
\end{array}$ \\
\hline use_newsitl & $\begin{array}{l}0.01 \\
(0.02)\end{array}$ & $\begin{array}{l}0.009 \\
(0.021)\end{array}$ & $\begin{array}{l}0.016 \\
(0.022)\end{array}$ & $\begin{array}{l}0.021 \\
(0.021)\end{array}$ & $\begin{array}{l}0.021 \\
(0.021)\end{array}$ & $\begin{array}{l}0.027 \\
(0.021)\end{array}$ & $\begin{array}{l}0.027 \\
(0.021)\end{array}$ \\
\hline use_screenshotsitl & $\begin{array}{l}0.006 \\
(0.02)\end{array}$ & $\begin{array}{l}0.002 \\
(0.021)\end{array}$ & $\begin{array}{l}0.006 \\
(0.021)\end{array}$ & $\begin{array}{l}-0.005 \\
(0.021)\end{array}$ & $\begin{array}{l}-0.005 \\
(0.021)\end{array}$ & $\begin{array}{l}0.002 \\
(0.021)\end{array}$ & $\begin{array}{l}0.002 \\
(0.021)\end{array}$ \\
\hline use_wiki itl & $\begin{array}{c}-0.05^{* *} \\
(0.018) \\
\end{array}$ & $\begin{array}{l}-0.055^{* *} \\
(0.019)\end{array}$ & $\begin{array}{l}-0.042^{*} \\
(0.019) \\
\end{array}$ & $\begin{array}{l}-0.031 \\
(0.019) \\
\end{array}$ & $\begin{array}{l}-0.031 \\
(0.019) \\
\end{array}$ & $\begin{array}{l}-0.018 \\
(0.019) \\
\end{array}$ & $\begin{array}{l}-0.018 \\
(0.019) \\
\end{array}$ \\
\hline Lang_Popitl & $\begin{array}{l}- \\
382.364 * * \\
* \\
(24.136)\end{array}$ & $\begin{array}{l}- \\
385.485 * * \\
* \\
(25.36)\end{array}$ & $\begin{array}{l}- \\
390.679 * * \\
* \\
(24.621)\end{array}$ & $\begin{array}{l}- \\
362.686^{* *} \\
* \\
(28.841)\end{array}$ & $\begin{array}{l}- \\
362.686^{* *} \\
* \\
(28.841)\end{array}$ & $\begin{array}{l}- \\
370.934 * * \\
* \\
(27.374)\end{array}$ & $\begin{array}{l}- \\
370.934 * * \\
* \\
(27.375)\end{array}$ \\
\hline Team_Tenure $_{\text {it } 1}$ & $\begin{array}{l}0.012 * * * \\
(0.002)\end{array}$ & $\begin{array}{l}0.012 * * * \\
(0.002)\end{array}$ & $\begin{array}{l}0.013 * * * \\
(0.002)\end{array}$ & $\begin{array}{l}-0.001 \\
(0.002) \\
\end{array}$ & $\begin{array}{l}-0.001 \\
(0.002)\end{array}$ & $\begin{array}{l}0.0002 \\
(0.002)\end{array}$ & $\begin{array}{l}0.0002 \\
(0.002)\end{array}$ \\
\hline Net_Sizeitl & $\begin{array}{l}-0.005^{* * *} \\
(0.001)\end{array}$ & $\begin{array}{l}-0.004 * * * \\
(0.001)\end{array}$ & $\begin{array}{l}-0.004 * * * \\
(0.001)\end{array}$ & $\begin{array}{l}-0.006^{* * * *} \\
(0.001)\end{array}$ & $\begin{array}{l}-0.006^{* * * *} \\
(0.001)\end{array}$ & $\begin{array}{l}-0.006^{* * *} \\
(0.001)\end{array}$ & $\begin{array}{l}-0.006^{* * *} \\
(0.001)\end{array}$ \\
\hline constant & $\begin{array}{l}-0.284+ \\
(0.171) \\
\end{array}$ & $\begin{array}{l}-0.223 \\
(0.168) \\
\end{array}$ & $\begin{array}{l}-0.238 \\
(0.169) \\
\end{array}$ & $\begin{array}{l}-0.18 \\
(0.171) \\
\end{array}$ & $\begin{array}{l}-0.004 \\
(0.172) \\
\end{array}$ & $\begin{array}{l}-0.187 \\
(0.173) \\
\end{array}$ & $\begin{array}{l}-0.021 \\
(0.174) \\
\end{array}$ \\
\hline \multicolumn{8}{|c|}{ Lang $_{i}$, License $_{i}$, Category $:$ Included but not reported } \\
\hline Log-pseudo likelihood & -6255.396 & -5741.350 & -5574.505 & -5733.573 & -5733.573 & -5566.659 & -5566.659 \\
\hline
\end{tabular}




\subsection{Post Hoc Investigations}

As reviewed earlier, the structural holes theory states that heterogeneous resources or information can be obtained because of the access to, and bridging of, different clusters of projects (i.e., structural holes). The OSS projects that contain a greater extent of structural holes in their resided networks are regarded as those that possess more heterogeneous resources (Ahuja 2000; Xiao and Tsui 2007). However, there could be exceptional cases. For instance, the score of structural holes within project $\mathrm{A}$ is significantly less than that of project $\mathrm{B}$ in the developeraffiliated network, but the developers of project A concurrently work for projects in 10 different project categories, whereas the developers of the project B only work on projects in two project categories. In this example, merely associating the extent of structural holes with resource heterogeneity is not appropriate. Accordingly, validating that resource heterogeneity indeed relates to the extent of structural holes is imperative. In doing so, Blau's heterogeneity index (1997), which has been employed in previous studies (Knight et al. 1999), was introduced to represent the categorical heterogeneity, which is mathematically expressed below.

$$
\text { Blau Index }=1-\sum_{k=1}^{s} p_{k}^{2}
$$

where $p$ is the proportion of connected projects in category $k$, and $s$ is the number of project categories (s is 18 in our context).

A higher value for the Blau Index implies a greater extent of resource heterogeneity. For instance, we suppose that one OSS project (in the Multimedia category) is connected with five other projects; that is, $\mathrm{P} 1-\mathrm{P} 5$, from five different project categories (Communication, Database, Desktop, Development, and Editors). In this case, the Blau Index ${ }^{10}$ is equal to 0.8. In this study,

\footnotetext{
10 This value is calculated as $1-\left[(1 / 5)^{2}+(1 / 5)^{2}+(1 / 5)^{2}+(1 / 5)^{2}+(1 / 5)^{2}\right]$.
} 
two Blau Indexes were computed for OSS project $i$ at $\mathrm{T}_{1}$ from the administrator-affiliated network (admin_blau $i t 1)$ and the developer-affiliated network (developer_blau $i t 1)$. The maximum values of admin_blauit 1 and developer_blau it $1_{1}$ are 0.898 and 0.906 , respectively. After that, the extent of structural holes was regressed on the Blau Indexes in each network with GLM. The coefficients of both $a d m i n \_b l a u_{i t 1}$ (coefficient $=0.390$ and standard error $=0.070$, p-value $=$ 0.001) and developer_blau it $_{\text {( }}$ (coefficient $=0.142$ and standard error $=0.082, \mathrm{p}$-value $=0.082$ ) were found to be significantly positive, thereby indicating that the OSS project with higher categorical heterogeneity in its interconnected projects indeed possessed more structural holes in both administrator- and developer-affiliated networks. Compared with developers, the administrators can more easily switch across different types of projects as soon as they have sharpened their project management or administration skills. In other words, the administrators can engage in more types of projects than the developers because of the flexibility of their knowledge. Thus, admin_blauitı has a stronger significance level than developer_blau $i t 1$.

Two methods were used to test the robustness of our analysis results. First, we replaced the GLMs by Beta regression to validate the robustness of our results. The beta regression can be used to estimate the proportional values bounded between 0 and 1 but excluding the 0 and 1 (Wooldridge 2010). By referring to the descriptive statistics in Table 2, the minimum value of two dependent variables is 0 . To maintain the consistency of the sample size, we referred to the transformation proposition by Smithson and Verkuilen (2006) and made the following transformation.

$$
\begin{aligned}
& \text { traffic_ratio }{ }_{i t 2}=(\text { traffic_ratio } i t 2 *(N-1)+0.5) /_{N} \\
& \text { develop_ratio }{ }_{i t 2}=\left(\text { develop_ratio }^{\prime}{ }_{i t 2} *(N-1)+0.5\right) /_{N}
\end{aligned}
$$


where $N$ is the total number of observations in the sample

The results are given in Tables 6 and 7. In a similar vein, the estimated coefficients for traffic_ratio' ${ }_{i t 2}$ are presented from Models 1 to 7 in Table 6 . The findings agree with those in Table 4. The results for develop_ratio' ${ }_{i t 2}$, as the dependent variable, are presented in Table 7 from Models 8 to 14 . There is a minor exception in the estimated coefficients of interactional terms presented in Model 13, where the maturity alleviated the negative relationship between the extent of structural holes and development intensity. Such an exceptional difference may result from the bias introduced by the transformation of dependent variables. By referring to the loglikelihood, the estimation from GLM (Tables 4 and 5) outperformed those from beta regressions. To further diagnose the results, we calculated the residuals of Model 13 in Table 5 and Model 13 in Table 7 and visualize their comparison in Figure 2 below. The scatter plot (Figure 2a) indicates substantial overlap, although the residuals from the GLM estimation have a smaller projection area, indicating better goodness-of-fit. The box plot confirms the scatter plots.

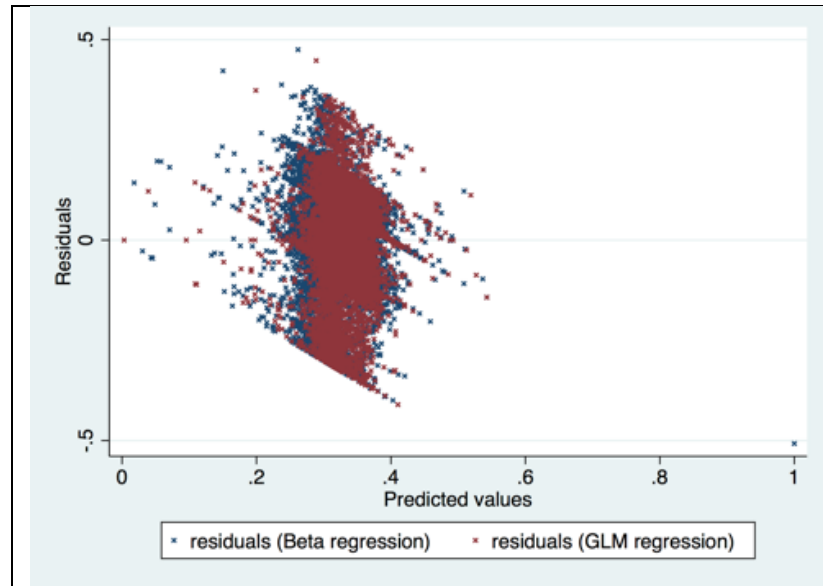

(a)

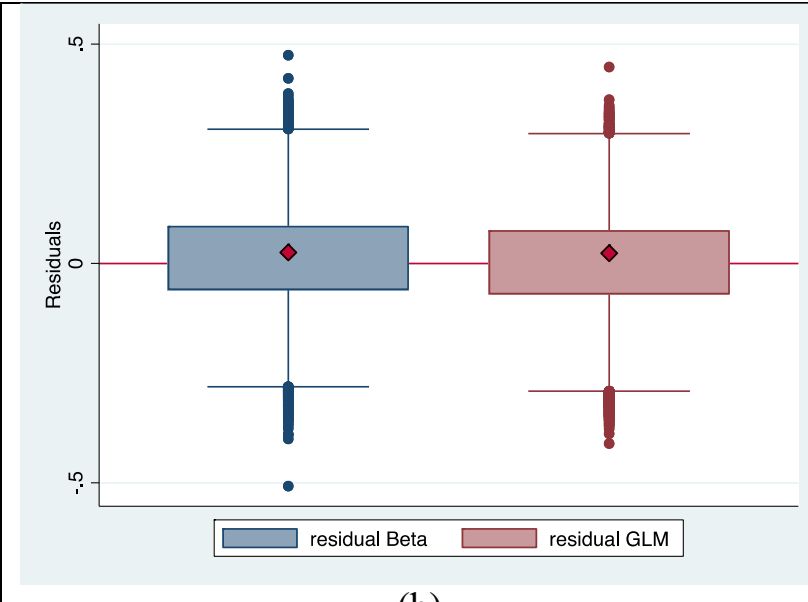

(b) 


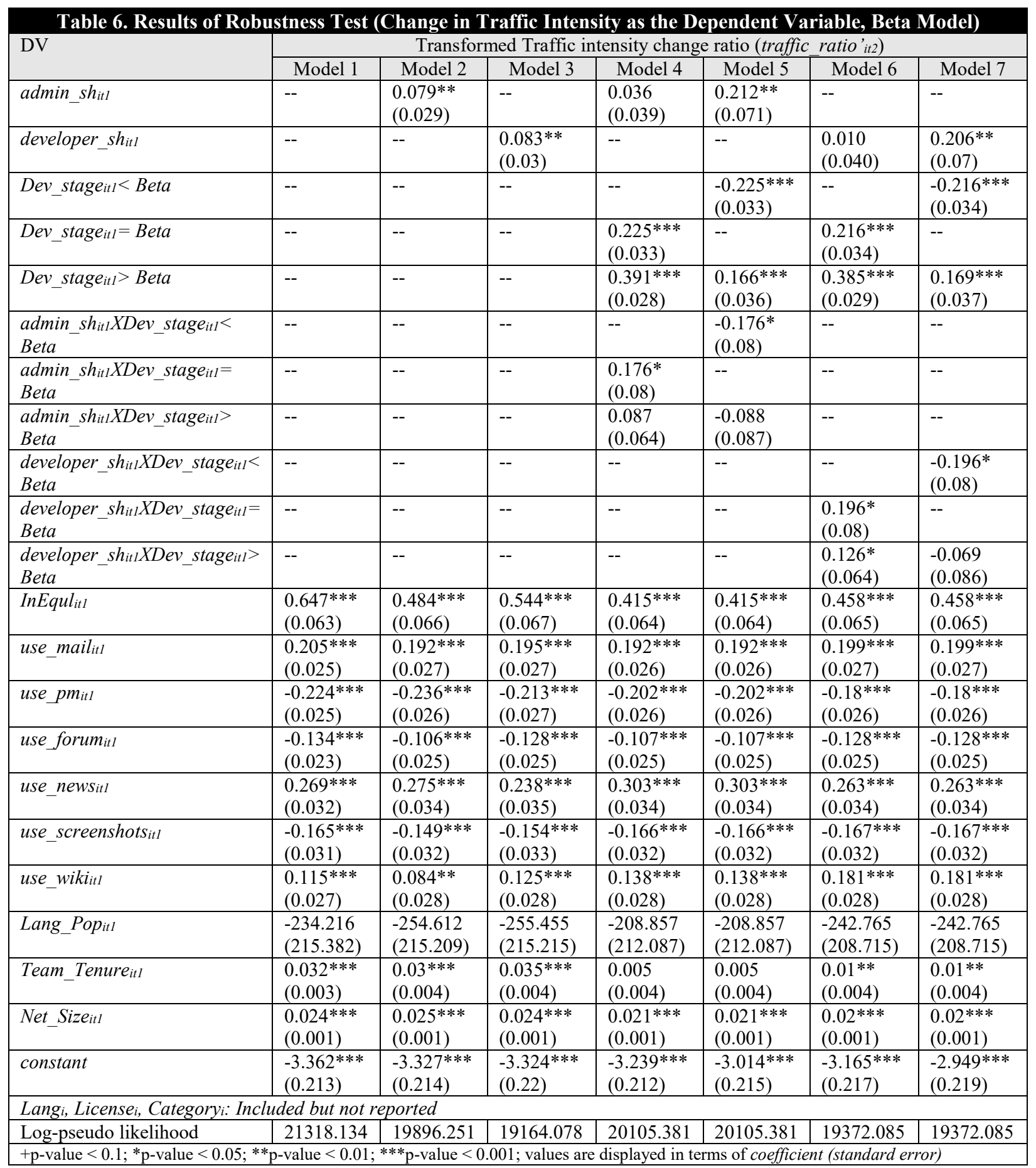




\begin{tabular}{|c|c|c|c|c|c|c|c|}
\hline \multirow[t]{2}{*}{ DV } & \multicolumn{7}{|c|}{ Transformed Development intensity change ratio (development_ratio ' ${ }^{\prime} t 2$ ) } \\
\hline & Model 8 & Model 9 & Model 10 & Model 11 & Model 12 & Model 13 & Model 14 \\
\hline admin_sh $h_{i t l}$ & -- & $\begin{array}{l}-0.256^{* * *} \\
(0.022)\end{array}$ & -- & $\begin{array}{l}-0.285^{* * *} \\
(0.029)\end{array}$ & $\begin{array}{l}-0.223 * * * \\
(0.052)\end{array}$ & -- & -- \\
\hline developer_shit1 & -- & -- & $\begin{array}{l}-0.179 * * * \\
(0.022)\end{array}$ & -- & -- & $\begin{array}{l}-0.233 * * * \\
(0.029)\end{array}$ & $\begin{array}{l}-0.129 * \\
(0.052)\end{array}$ \\
\hline Dev_stage $i t 1<$ Beta & -- & -- & -- & -- & $\begin{array}{l}-0.201 * * * \\
(0.024)\end{array}$ & -- & $\begin{array}{l}-0.195 * * * \\
(0.024)\end{array}$ \\
\hline Dev_stage $i t 1=$ Beta & -- & -- & -- & $\begin{array}{l}0.201^{* * *} \\
(0.024)\end{array}$ & -- & $\begin{array}{l}0.195 * * * \\
(0.024)\end{array}$ & -- \\
\hline Dev_stage $i t 1>$ Beta & -- & -- & -- & $\begin{array}{l}0.213 * * * \\
(0.021)\end{array}$ & $\begin{array}{l}0.012 \\
(0.026)\end{array}$ & $\begin{array}{l}0.199 * * * \\
(0.021)\end{array}$ & $\begin{array}{l}0.004 \\
(0.027)\end{array}$ \\
\hline $\begin{array}{l}\text { admin_shitlXDev_stage } i t 1< \\
\text { Beta }\end{array}$ & -- & -- & -- & -- & $\begin{array}{l}-0.062 \\
(0.059)\end{array}$ & -- & -- \\
\hline $\begin{array}{l}\text { admin_shitlXDev_stage } i t 1= \\
\text { Beta }\end{array}$ & -- & -- & -- & $\begin{array}{l}0.062 \\
(0.059)\end{array}$ & -- & -- & -- \\
\hline $\begin{array}{l}\text { admin_sh } h_{i t 1} X D e v \_s t a g e_{i t 1}> \\
\text { Beta }\end{array}$ & -- & -- & -- & $\begin{array}{l}0.088+ \\
(0.049)\end{array}$ & $\begin{array}{l}0.027 \\
(0.066)\end{array}$ & -- & -- \\
\hline $\begin{array}{l}\text { developer_sh } i t 1 X D e v \_s t a g e e_{i t 1}< \\
\text { Beta }\end{array}$ & -- & -- & -- & -- & -- & -- & $\begin{array}{l}-0.104+ \\
(0.059)\end{array}$ \\
\hline $\begin{array}{l}\text { developer_sh }{ }_{i t 1} X D e v \_s t a g e_{i t 1}= \\
\text { Beta }\end{array}$ & -- & -- & -- & -- & -- & $\begin{array}{l}0.104+ \\
(0.059)\end{array}$ & -- \\
\hline $\begin{array}{l}\text { developer_sh }{ }_{i t 1} X D e v \_s t a g e_{i t 1}> \\
\text { Beta }\end{array}$ & -- & -- & -- & -- & -- & $\begin{array}{l}0.131 * * \\
(0.048)\end{array}$ & $\begin{array}{l}0.026 \\
(0.064)\end{array}$ \\
\hline InEqulitl $_{1}$ & $\begin{array}{l}-0.154 * * * \\
(0.04)\end{array}$ & $\begin{array}{l}-0.141 * * * \\
(0.042)\end{array}$ & $\begin{array}{l}-0.111^{* *} \\
(0.042)\end{array}$ & $\begin{array}{l}-0.183 * * * \\
(0.042)\end{array}$ & $\begin{array}{l}-0.183 * * * \\
(0.042)\end{array}$ & $\begin{array}{l}-0.159 * * * \\
(0.042)\end{array}$ & $\begin{array}{l}-0.159 * * * \\
(0.042)\end{array}$ \\
\hline use_mailitl & $\begin{array}{l}-0.033+ \\
(0.018) \\
\end{array}$ & $\begin{array}{l}-0.032+ \\
(0.019) \\
\end{array}$ & $\begin{array}{l}-0.046^{*} \\
(0.019) \\
\end{array}$ & $\begin{array}{l}-0.033+ \\
(0.019) \\
\end{array}$ & $\begin{array}{l}-0.033+ \\
(0.019) \\
\end{array}$ & $\begin{array}{l}-0.046^{*} \\
(0.019) \\
\end{array}$ & $\begin{array}{l}-0.046^{*} \\
(0.019) \\
\end{array}$ \\
\hline use_pmitl & $\begin{array}{l}-0.037^{*} \\
(0.019) \\
\end{array}$ & $\begin{array}{l}-0.046^{*} \\
(0.02)\end{array}$ & $\begin{array}{l}-0.026 \\
(0.02)\end{array}$ & $\begin{array}{l}-0.033+ \\
(0.019) \\
\end{array}$ & $\begin{array}{l}-0.033+ \\
(0.019) \\
\end{array}$ & $\begin{array}{l}-0.014 \\
(0.019)\end{array}$ & $\begin{array}{l}-0.014 \\
(0.019)\end{array}$ \\
\hline use_forum $_{\text {it } 1}$ & \begin{tabular}{|l|}
0.021 \\
$(0.017)$ \\
\end{tabular} & $\begin{array}{l}0.021 \\
(0.018) \\
\end{array}$ & $\begin{array}{l}0.024 \\
(0.018) \\
\end{array}$ & $\begin{array}{l}0.027 \\
(0.018) \\
\end{array}$ & $\begin{array}{l}0.027 \\
(0.018) \\
\end{array}$ & $\begin{array}{l}0.03+ \\
(0.018) \\
\end{array}$ & $\begin{array}{l}0.03+ \\
(0.018) \\
\end{array}$ \\
\hline use_newsit1 & $\begin{array}{l}0.054^{*} \\
(0.024) \\
\end{array}$ & $\begin{array}{l}0.057^{*} \\
(0.025)\end{array}$ & $\begin{array}{l}0.061^{*} \\
(0.025)\end{array}$ & $\begin{array}{l}0.074 * * \\
(0.025) \\
\end{array}$ & $\begin{array}{l}0.074 * * \\
(0.025) \\
\end{array}$ & $\begin{array}{l}0.078^{* *} \\
(0.025) \\
\end{array}$ & $\begin{array}{l}0.078^{* *} \\
(0.025) \\
\end{array}$ \\
\hline use_screenshotsit & \begin{tabular}{|l|}
0.013 \\
$(0.024)$ \\
\end{tabular} & $\begin{array}{l}0.007 \\
(0.025)\end{array}$ & $\begin{array}{l}0.013 \\
(0.025)\end{array}$ & $\begin{array}{l}0.001 \\
(0.025)\end{array}$ & $\begin{array}{l}0.001 \\
(0.025)\end{array}$ & $\begin{array}{l}0.011 \\
(0.025)\end{array}$ & $\begin{array}{l}0.011 \\
(0.025)\end{array}$ \\
\hline use_wikititl & $\begin{array}{l}-0.066^{* * *} \\
(0.02) \\
\end{array}$ & $\begin{array}{l}-0.08 * * * \\
(0.021)\end{array}$ & $\begin{array}{l}-0.066^{* *} \\
(0.021)\end{array}$ & $\begin{array}{l}-0.05^{*} \\
(0.021)\end{array}$ & $\begin{array}{l}-0.05^{*} \\
(0.021)\end{array}$ & $\begin{array}{l}-0.035+ \\
(0.021)\end{array}$ & $\begin{array}{l}-0.035+ \\
(0.021)\end{array}$ \\
\hline Lang_Pop ${ }_{i t 1}$ & \begin{tabular}{|l|}
-196.529 \\
$(248.034)$ \\
\end{tabular} & $\begin{array}{l}-215.185 \\
(247.516) \\
\end{array}$ & $\begin{array}{l}-217.211 \\
(246.111) \\
\end{array}$ & $\begin{array}{l}-177.077 \\
(246.182) \\
\end{array}$ & $\begin{array}{l}-177.077 \\
(246.182) \\
\end{array}$ & $\begin{array}{l}-190.493 \\
(244.696) \\
\end{array}$ & $\begin{array}{l}-190.493 \\
(244.696)\end{array}$ \\
\hline Team_Tenure $e_{i t 1}$ & $\begin{array}{l}0.02 * * * \\
(0.003) \\
\end{array}$ & $\begin{array}{l}0.021 * * * \\
(0.003)\end{array}$ & $\begin{array}{l}0.022 * * * \\
(0.003)\end{array}$ & $\begin{array}{l}0.005+ \\
(0.003) \\
\end{array}$ & $\begin{array}{l}0.005+ \\
(0.003) \\
\end{array}$ & $\begin{array}{l}0.005+ \\
(0.003) \\
\end{array}$ & $\begin{array}{l}0.005+ \\
(0.003) \\
\end{array}$ \\
\hline Net_Sizeitl & $\begin{array}{l}-0.006^{* * * *} \\
(0.001)\end{array}$ & $\begin{array}{l}-0.005^{* * *} \\
(0.001)\end{array}$ & $\begin{array}{l}-0.004^{* * * *} \\
(0.001)\end{array}$ & $\begin{array}{l}-0.008^{* * *} \\
(0.001)\end{array}$ & $\begin{array}{l}-0.008^{* * *} \\
(0.001)\end{array}$ & $\begin{array}{l}-0.008^{* * *} \\
(0.001)\end{array}$ & $\begin{array}{l}-0.008 * * * \\
(0.001)\end{array}$ \\
\hline constant & $\begin{array}{l}-0.458^{* *} \\
(0.152) \\
\end{array}$ & $\begin{array}{l}-0.371^{*} \\
(0.151) \\
\end{array}$ & $\begin{array}{l}-0.426^{* *} \\
(0.153) \\
\end{array}$ & $\begin{array}{l}-0.316^{*} \\
(0.15) \\
\end{array}$ & $\begin{array}{l}-0.115 \\
(0.151) \\
\end{array}$ & $\begin{array}{l}-0.361^{*} \\
(0.152)\end{array}$ & $\begin{array}{l}-0.166 \\
(0.154) \\
\end{array}$ \\
\hline \multicolumn{8}{|c|}{ Lang $_{i}$, License ${ }_{i}$, Category ${ }_{i}$ : Included but not reported } \\
\hline Log-pseudo likelihood & 7848.265 & 7303.360 & 7108.576 & 7449.9903 & 7449.9903 & 7257.874 & 7257.7546 \\
\hline
\end{tabular}


In addition, we computed the extent of structural holes by each project category to further confirm that the contingent role of interproject connectedness in influencing the change in popularity and knowledge creation. In this computation, for each OSS project, its connected projects that emerge from the other project categories are excluded. Eventually, 36 distinct affiliation networks were constructed based on two roles of contributors, namely, administrators (admin_intra_sh $\left.h_{i t 1}\right)$ and developers (developer_intra_sh $\left.h_{i t 1}\right)$. Table 8 shows the overall results for the change in traffic intensity as the dependent variable. In Table 9, the dependent variable is the change to the development intensity. The base models are not presented as the results are generally consistent with the previous findings. Interestingly, the negative relationship between the degree of structural holes and development intensity was enhanced when comparing projects at the post-beta phase with those at the pre-beta phase (Model 9 in Table 9). The most mature OSS projects might be reluctant to assimilate externally sourced information due to the inertia and sunk costs in ongoing developments or operations (Zahra and Hayton 2008). 


\begin{tabular}{|c|c|c|c|c|c|c|}
\hline \multirow[t]{2}{*}{ DV } & \multicolumn{6}{|c|}{ Traffic intensity change ratio (traffic_ratio ${ }_{\text {it } 2 \text { ) }}$} \\
\hline & Model 1 & Model 2 & Model 3 & Model 4 & Model 5 & Model 6 \\
\hline admin_intra_sh $h_{i t 1}$ & $\begin{array}{l}0.25 * * * \\
(0.051)\end{array}$ & -- & $\begin{array}{l}0.052 \\
(0.043)\end{array}$ & $\begin{array}{l}0.269 * * * \\
(0.067)\end{array}$ & -- & -- \\
\hline developer_intra_shitl & -- & $\begin{array}{l}0.235^{* * *} \\
(0.058) \\
\end{array}$ & -- & -- & $\begin{array}{l}0.061 \\
(0.045) \\
\end{array}$ & $\begin{array}{l}0.29^{* * *} \\
(0.067) \\
\end{array}$ \\
\hline Dev_stage $e_{i t 1}<$ Beta & -- & -- & -- & $\begin{array}{l}-0.275^{* * * *} \\
(0.034)\end{array}$ & -- & $\begin{array}{l}-0.265^{* * * *} \\
(0.034)\end{array}$ \\
\hline Dev_stage $e_{i t 1}=$ Beta & -- & -- & $\begin{array}{l}0.275^{* * *} \\
(0.034)\end{array}$ & -- & $\begin{array}{l}0.265^{* * *} \\
(0.034)\end{array}$ & -- \\
\hline Dev_stage $e_{i t 1}>$ Beta & -- & -- & $\begin{array}{l}0.479 * * * \\
(0.029)\end{array}$ & $\begin{array}{l}0.204 * * * \\
(0.035)\end{array}$ & $\begin{array}{l}0.46^{* * *} \\
(0.029)\end{array}$ & $\begin{array}{l}0.195^{* * *} \\
(0.035)\end{array}$ \\
\hline $\begin{array}{l}\text { admin_shitlXDev_stage } i t 1< \\
\text { Beta }\end{array}$ & -- & -- & -- & $\begin{array}{l}-0.217 * * \\
(0.078)\end{array}$ & -- & -- \\
\hline $\begin{array}{l}\text { admin_shitlXDev_stage } i t 1= \\
\text { Beta }\end{array}$ & -- & -- & $\begin{array}{l}0.217 * * \\
(0.078)\end{array}$ & -- & -- & -- \\
\hline $\begin{array}{l}\text { admin_sh } h_{i t l} X D e v \_s t a g e_{i t 1}> \\
\text { Beta }\end{array}$ & -- & -- & $\begin{array}{l}0.067 \\
(0.065) \\
\end{array}$ & $\begin{array}{l}-0.15+ \\
(0.081) \\
\end{array}$ & -- & -- \\
\hline $\begin{array}{l}\text { developer_sh }{ }_{i t 1} X D e v \_s t a g e_{i t 1}< \\
\text { Beta }\end{array}$ & -- & -- & -- & -- & -- & $\begin{array}{l}-0.229 * * \\
(0.078)\end{array}$ \\
\hline $\begin{array}{l}\text { developer_sh }{ }_{i t l} X D e v \_s t a g e_{i t l}= \\
\text { Beta }\end{array}$ & -- & -- & -- & -- & $\begin{array}{l}0.229 * * \\
(0.078)\end{array}$ & -- \\
\hline $\begin{array}{l}\text { developer_sh }{ }_{i t 1} X D e v \_s t a g e_{i t 1}> \\
\text { Beta }\end{array}$ & -- & -- & -- & -- & $\begin{array}{l}0.085 \\
(0.068) \\
\end{array}$ & $\begin{array}{l}-0.144+ \\
(0.08) \\
\end{array}$ \\
\hline InEqulitl & $\begin{array}{l}0.821^{* * *} \\
(0.093)\end{array}$ & $\begin{array}{l}0.92 * * * \\
(0.093)\end{array}$ & $\begin{array}{l}0.678^{* * *} \\
(0.079)\end{array}$ & $\begin{array}{l}0.678^{* * *} \\
(0.079)\end{array}$ & $\begin{array}{l}0.755^{* * *} \\
(0.081)\end{array}$ & $\begin{array}{l}0.755^{* * *} \\
(0.081)\end{array}$ \\
\hline use_mail $l_{i t l}$ & $\begin{array}{l}0.155^{* * *} \\
(0.03)\end{array}$ & $\begin{array}{l}0.14 * * * \\
(0.03)\end{array}$ & $\begin{array}{l}0.14 * * * \\
(0.029)\end{array}$ & $\begin{array}{l}0.14 * * * \\
(0.029)\end{array}$ & $\begin{array}{l}0.131 * * * \\
(0.029)\end{array}$ & $\begin{array}{l}0.131^{* * *} \\
(0.029)\end{array}$ \\
\hline use $p m_{i t l}$ & $\begin{array}{l}-0.285^{* * *} \\
(0.028)\end{array}$ & $\begin{array}{l}-0.258^{* * *} \\
(0.027)\end{array}$ & $\begin{array}{l}-0.246^{* * *} \\
(0.027)\end{array}$ & $\begin{array}{l}-0.246^{* * *} \\
(0.027)\end{array}$ & $\begin{array}{l}-0.227^{* * * *} \\
(0.026)\end{array}$ & $\begin{array}{l}-0.227^{* * * *} \\
(0.026)\end{array}$ \\
\hline use_forum $_{\text {itl }}$ & $\begin{array}{l}-0.168 * * * \\
(0.028)\end{array}$ & $\begin{array}{l}-0.171^{* * *} \\
(0.026)\end{array}$ & $\begin{array}{l}-0.156^{* * *} \\
(0.026)\end{array}$ & $\begin{array}{l}-0.156^{* * *} \\
(0.026)\end{array}$ & $\begin{array}{l}-0.161^{* * *} \\
(0.026)\end{array}$ & $\begin{array}{l}-0.161 * * * \\
(0.026)\end{array}$ \\
\hline use_newsitl & $\begin{array}{l}0.108^{* *} \\
(0.037)\end{array}$ & $\begin{array}{l}0.091^{*} \\
(0.037)\end{array}$ & $\begin{array}{l}0.135^{* * *} \\
(0.036)\end{array}$ & $\begin{array}{l}0.135^{* * * *} \\
(0.036) \\
\end{array}$ & $\begin{array}{l}0.117 * * * \\
(0.035) \\
\end{array}$ & $\begin{array}{l}0.117 * * * \\
(0.035)\end{array}$ \\
\hline use_screenshotsitl & $\begin{array}{l}-0.103 * * \\
(0.034)\end{array}$ & $\begin{array}{l}-0.112^{* * * *} \\
(0.034)\end{array}$ & $\begin{array}{l}-0.116^{* * *} \\
(0.033)\end{array}$ & $\begin{array}{l}-0.116^{* * *} \\
(0.033)\end{array}$ & $\begin{array}{l}-0.116^{* * * *} \\
(0.033)\end{array}$ & $\begin{array}{l}-0.116^{* * *} \\
(0.033)\end{array}$ \\
\hline use_wikititl & $\begin{array}{l}0.157^{* * *} \\
(0.031)\end{array}$ & $\begin{array}{l}0.139 * * * \\
(0.031)\end{array}$ & $\begin{array}{l}0.215^{* * *} \\
(0.03)\end{array}$ & $\begin{array}{l}0.215^{* * *} \\
(0.03)\end{array}$ & $\begin{array}{l}0.193 * * * \\
(0.03)\end{array}$ & $\begin{array}{l}0.193 * * * \\
(0.03)\end{array}$ \\
\hline Lang_Pop ${ }_{i t 1}$ & $\begin{array}{l}-158.107+ \\
(81.124)\end{array}$ & $\begin{array}{l}-205.529^{* *} \\
(77.221)\end{array}$ & $\begin{array}{l}-135.315^{*} \\
(67.399)\end{array}$ & $\begin{array}{l}-135.315^{*} \\
(67.398)\end{array}$ & $\begin{array}{l}-181.888^{* *} \\
(66.949)\end{array}$ & $\begin{array}{l}-181.888^{* *} \\
(66.949)\end{array}$ \\
\hline Team_Tenureit1 & $\begin{array}{l}0.025^{* * *} \\
(0.004) \\
\end{array}$ & $\begin{array}{l}0.025^{* * *} \\
(0.004) \\
\end{array}$ & $\begin{array}{l}-0.01 * \\
(0.004) \\
\end{array}$ & $\begin{array}{l}-0.01 * \\
(0.004)\end{array}$ & $\begin{array}{l}-0.01 * \\
(0.005) \\
\end{array}$ & $\begin{array}{l}-0.01^{*} \\
(0.005)\end{array}$ \\
\hline Net_Size $i t 1$ & $\begin{array}{l}0.013^{* *} \\
(0.004)\end{array}$ & $\begin{array}{l}0.013^{* *} \\
(0.004)\end{array}$ & $\begin{array}{l}0.01^{* *} \\
(0.004)\end{array}$ & $\begin{array}{l}0.01^{* *} \\
(0.004)\end{array}$ & $\begin{array}{l}0.01 * * \\
(0.004)\end{array}$ & $\begin{array}{l}0.01^{* *} \\
(0.004)\end{array}$ \\
\hline constant & $\begin{array}{l}-3.288^{* * * *} \\
(0.226)\end{array}$ & $\begin{array}{l}-3.265^{* * *} \\
(0.227)\end{array}$ & $\begin{array}{l}-3.16 * * * \\
(0.224)\end{array}$ & $\begin{array}{l}-2.885^{* * *} \\
(0.226)\end{array}$ & $\begin{array}{l}-3.12 * * * \\
(0.225)\end{array}$ & $\begin{array}{l}-2.855^{* * *} \\
(0.227)\end{array}$ \\
\hline Lang $_{i}$, License $_{i}$, Category ${ }_{i}$ : Incl & ded but not 1 & orted & & & & \\
\hline Log-pseudo likelihood & -2507.366 & -2497.641 & -2490.906 & -2490.906 & -2481.859 & -2481.859 \\
\hline
\end{tabular}




\begin{tabular}{|c|c|c|c|c|c|c|}
\hline \multirow[t]{2}{*}{ DV } & \multicolumn{6}{|c|}{ Development intensity change ratio (development_ratioit2) } \\
\hline & Model 7 & Model 8 & Model 9 & Model 10 & Model 11 & Model 12 \\
\hline admin_intra_sh $h_{i t l}$ & $\begin{array}{l}-0.154 * * * \\
(0.033)\end{array}$ & -- & $\begin{array}{l}-0.098^{*} \\
(0.046) \\
\end{array}$ & $\begin{array}{l}-0.193 * \\
(0.077) \\
\end{array}$ & -- & -- \\
\hline developer_intra_sh ${ }_{i t 1}$ & -- & $\begin{array}{l}-0.139 * * * \\
(0.032)\end{array}$ & -- & -- & $\begin{array}{l}-0.141 * * \\
(0.047) \\
\end{array}$ & $\begin{array}{l}-0.123+ \\
(0.069) \\
\end{array}$ \\
\hline Dev_stage $i t 1<$ Beta & -- & -- & -- & $\begin{array}{l}-0.184 * * * \\
(0.015)\end{array}$ & -- & $\begin{array}{l}-0.182 * * * \\
(0.015)\end{array}$ \\
\hline Dev_stage $i t 1=$ Beta & -- & -- & $\begin{array}{l}0.184 * * * \\
(0.015)\end{array}$ & -- & $\begin{array}{l}0.182^{* * *} \\
(0.015)\end{array}$ & -- \\
\hline Dev_stageitl $>$ Beta & -- & -- & $\begin{array}{l}0.186^{* * *} \\
(0.013) \\
\end{array}$ & $\begin{array}{l}0.002 \\
(0.015) \\
\end{array}$ & $\begin{array}{l}0.171^{* * *} \\
(0.013) \\
\end{array}$ & $\begin{array}{l}-0.012 \\
(0.015) \\
\end{array}$ \\
\hline $\begin{array}{l}\text { admin_sh } h_{i t 1} X D e v \_s t a g e_{i t 1}< \\
\text { Beta }\end{array}$ & -- & -- & -- & $\begin{array}{l}0.095 \\
(0.089) \\
\end{array}$ & -- & -- \\
\hline $\begin{array}{l}\text { admin_shitlXDev_stage } i t 1= \\
\text { Beta }\end{array}$ & -- & -- & $\begin{array}{l}-0.095 \\
(0.089) \\
\end{array}$ & -- & -- & -- \\
\hline $\begin{array}{l}\text { admin_sh } \\
\text { Beta }\end{array}$ & -- & -- & $\begin{array}{l}-0.143^{*} \\
(0.068)\end{array}$ & $\begin{array}{l}-0.049 \\
(0.09)\end{array}$ & -- & -- \\
\hline $\begin{array}{l}\text { developer_sh }{ }_{i t 1} X D e v \_s t a g e_{i t 1}< \\
\text { Beta }\end{array}$ & -- & -- & -- & -- & -- & $\begin{array}{l}-0.018 \\
(0.082)\end{array}$ \\
\hline $\begin{array}{l}\text { developer_shitlXDev_stage } i t 1= \\
\text { Beta }\end{array}$ & -- & -- & -- & -- & $\begin{array}{l}0.018 \\
(0.082)\end{array}$ & -- \\
\hline $\begin{array}{l}\text { developer_sh }{ }_{i t 1} X D e v \_s t a g e_{i t 1}> \\
\text { Beta }\end{array}$ & -- & -- & -- & -- & $\begin{array}{l}-0.004 \\
(0.066)\end{array}$ & $\begin{array}{l}-0.021 \\
(0.081)\end{array}$ \\
\hline InEqul $_{\text {itl }}$ & $\begin{array}{l}-0.137 * * * \\
(0.035) \\
\end{array}$ & $\begin{array}{l}-0.091 * * \\
(0.035) \\
\end{array}$ & $\begin{array}{l}-0.168 * * * \\
(0.035)\end{array}$ & $\begin{array}{l}-0.168^{* * *} \\
(0.035) \\
\end{array}$ & $\begin{array}{l}-0.129 * * * \\
(0.035)\end{array}$ & $\begin{array}{l}-0.129 * * * \\
(0.035)\end{array}$ \\
\hline use_mailitl & $\begin{array}{l}-0.045^{* *} \\
(0.017)\end{array}$ & $\begin{array}{l}-0.055^{* * *} \\
(0.017)\end{array}$ & $\begin{array}{l}-0.047^{* *} \\
(0.017)\end{array}$ & $\begin{array}{l}-0.047^{* *} \\
(0.017)\end{array}$ & $\begin{array}{l}-0.056^{* * *} \\
(0.017)\end{array}$ & $\begin{array}{l}-0.056^{* * *} \\
(0.017)\end{array}$ \\
\hline use $p m_{i t 1}$ & $\begin{array}{l}-0.025 \\
(0.017) \\
\end{array}$ & $\begin{array}{l}-0.019 \\
(0.017)\end{array}$ & $\begin{array}{l}-0.012 \\
(0.017)\end{array}$ & $\begin{array}{l}-0.012 \\
(0.017)\end{array}$ & $\begin{array}{l}-0.01 \\
(0.017)\end{array}$ & $\begin{array}{l}-0.01 \\
(0.017)\end{array}$ \\
\hline use_forum $_{\text {itl }}$ & $\begin{array}{l}0.006 \\
(0.016)\end{array}$ & $\begin{array}{l}0.01 \\
(0.016)\end{array}$ & $\begin{array}{l}0.008 \\
(0.016)\end{array}$ & $\begin{array}{l}0.008 \\
(0.016)\end{array}$ & $\begin{array}{l}0.012 \\
(0.016)\end{array}$ & $\begin{array}{l}0.012 \\
(0.016)\end{array}$ \\
\hline use_newsitl & $\begin{array}{l}0.041+ \\
(0.024)\end{array}$ & $\begin{array}{l}0.034 \\
(0.023)\end{array}$ & $\begin{array}{l}0.053^{*} \\
(0.023) \\
\end{array}$ & $\begin{array}{l}0.053^{*} \\
(0.023)\end{array}$ & $\begin{array}{l}0.047^{*} \\
(0.023)\end{array}$ & $\begin{array}{l}0.047^{*} \\
(0.023)\end{array}$ \\
\hline use_screenshotsitl & $\begin{array}{l}-0.002 \\
(0.022)\end{array}$ & $\begin{array}{l}0.012 \\
(0.022)\end{array}$ & $\begin{array}{l}-0.01 \\
(0.022)\end{array}$ & $\begin{array}{l}-0.01 \\
(0.022)\end{array}$ & $\begin{array}{l}0.007 \\
(0.022)\end{array}$ & $\begin{array}{l}0.007 \\
(0.022)\end{array}$ \\
\hline use_wikititl & $\begin{array}{l}-0.056^{* *} \\
(0.021)\end{array}$ & $\begin{array}{l}-0.053^{*} \\
(0.021)\end{array}$ & $\begin{array}{l}-0.034 \\
(0.021)\end{array}$ & $\begin{array}{l}-0.034 \\
(0.021)\end{array}$ & $\begin{array}{l}-0.03 \\
(0.021)\end{array}$ & $\begin{array}{l}-0.03 \\
(0.021)\end{array}$ \\
\hline Lang_Pop $_{i t 1}$ & $\begin{array}{l}- \\
378.693 * * * \\
(26.261)\end{array}$ & $\begin{array}{l}- \\
379.869 * * * \\
(26.382) \\
\end{array}$ & $\begin{array}{l}- \\
356.879 * * * \\
(29.402)\end{array}$ & $\begin{array}{l}- \\
356.879 * * * \\
(29.402)\end{array}$ & $\begin{array}{l}- \\
362.038 * * * \\
(29.016)\end{array}$ & $\begin{array}{l}362.038^{* * *} \\
(29.016) \\
\end{array}$ \\
\hline Team_TenureitI & $\begin{array}{l}0.01 * * * \\
(0.002) \\
\end{array}$ & $\begin{array}{l}0.013 * * * \\
(0.003)\end{array}$ & $\begin{array}{l}-0.003 \\
(0.003) \\
\end{array}$ & $\begin{array}{l}-0.003 \\
(0.003) \\
\end{array}$ & $\begin{array}{l}-0.001 \\
(0.003) \\
\end{array}$ & $\begin{array}{l}-0.001 \\
(0.003) \\
\end{array}$ \\
\hline Net_Sizeitl & $\begin{array}{l}-0.004 * * * \\
(0.001)\end{array}$ & $\begin{array}{l}-0.004^{* * *} \\
(0.001)\end{array}$ & $\begin{array}{l}-0.006^{* * *} \\
(0.001)\end{array}$ & $\begin{array}{l}-0.006^{* * *} \\
(0.001)\end{array}$ & $\begin{array}{l}-0.006^{* * *} \\
(0.001)\end{array}$ & $\begin{array}{l}-0.006^{* * *} \\
(0.001)\end{array}$ \\
\hline constant & $\begin{array}{l}-0.322^{*} \\
(0.159)\end{array}$ & $\begin{array}{l}-0.362^{*} \\
(0.159)\end{array}$ & $\begin{array}{l}-0.285+ \\
(0.164)\end{array}$ & $\begin{array}{l}-0.101 \\
(0.165)\end{array}$ & $\begin{array}{l}-0.317+ \\
(0.164)\end{array}$ & $\begin{array}{l}-0.135 \\
(0.165)\end{array}$ \\
\hline Lang $_{i}$, License $_{i}$, Category $i:$ Incl & ded but not rel & orted & & & & \\
\hline Log-pseudo likelihood & -4747.1604 & -4683.228 & -4740.445 & -4740.445 & -4676.736 & -4676.736 \\
\hline
\end{tabular}


We conducted several ad hoc tests to rule out other potential alternative explanations to strengthen the findings. First, we conducted two correlation analyses to rule out the possibility of interdependency between two dependent variables. This concern arises because the extent of structural holes in both administrator-affiliated network and the developeraffiliated network has an opposite impact on the changes in traffic intensity and development intensity, respectively. We referred to our proposed measurement of traffic intensity $\left(T R F_{i t}\right)$ and development intensity $\left(D V P_{i t}\right)$ in $\$ 4.2$ to calculate their values at $T 1$, namely $T R F_{i t 1}$ and $D V P_{i t l}$, respectively, and calculated their correlation. Their correlation value is 0.053 , which indicates that there is no interrelation between traffic intensity and development intensity. To further confirm such a conclusion, we also calculated the correlation between two dependent variables, namely traffic_ratio ${ }_{i t 2}$ and development_ratio it $_{2}$, used in the preceding analysis.

The low correlation value (0.039) between these two variables reaches a consistent conclusion.

Second, we calculated the extents of structural holes in the administrator-affiliated network (admin_sh $\left.h_{i t 2}\right)$ and developer-affiliated network (developer_sh $\left.h_{i t 2}\right)$ at $\mathrm{T}_{2}$ (Dec 2010) and statistically compared them with those at T1, namely admin_sh $h_{i t 1}$ and developer_sh $h_{i t 1}$. This approach can rule out the alternative explanation that changes in the dependent variables were influenced by the phases of the network (i.e., network growth or attenuation). The results from the paired sample t-test ${ }^{11}$ indicate that there is no difference in the extent of structural holes between $T_{1}$ and $T_{2}$. Such results are equitable. On the one hand, some unconnected OSS projects may be bridged by newly affiliated contributors, which reduces the extent of structural holes and increases the network closure; on the other hand, the

\footnotetext{
${ }^{11}$ We employed the paired sample t-test to statistically validate the difference between two timestamps. In the administrator-affiliated network, the difference in mean values between two timestamps is -0.184 and the $95 \%$ confidence interval is from -0.191 to -0.176 . Thus, the null hypothesis is not rejected. In a similar vein, the difference in mean values in the developer-affiliated network between the two timestamps is -0.126 , which is also located within the $95 \%$ confidence interval (i.e., from -0.131 to -0.121 ). Thus, the null hypothesis is not rejected, either.
} 
network of a focal OSS project can be expanded with the newly attached ones, which will increase the extent of the structural holes as well. Both circumstances concurrently exist. Thus, our focal network does not fluctuate drastically over time.

\section{Discussions}

\subsection{Theoretical and Practical Implications}

Compare to previous studies that briefly explained the relationship between network structure and OSS project success with social capital (Grewal et al. 2006; Singh 2010; Singh et al. 2011a), we deliberated how network structures characterized OSS project success with due consideration of OSS innovation mechanisms. This contributed to complementing the OSS innovation model from a more holistic perspective from two aspects. Firstly, previous studies have an overwhelming emphasis on the role of motivation or incentives in constructing the innovation model of OSS (von Hippel and von Krogh 2003). We acknowledge their importance to account for individual participation in OSS innovation but further urge institutionalizing interproject connectedness in the theorization of OSS innovation model. Secondly, rather than following the prior OSS studies that assessed the success of an OSS project from a single dimension, such as the number of downloads or the volume of CVS commits and others (Subramaniam et al. 2009; Singh et al. 2011a), we provided a more holistic investigation to the OSS performance. By considering both network structure and wholesome assessment of OSS performance, we evidently verified our overarching proposition that the OSS interproject connectedness has a contingent impact on OSS project success. To the best of our knowledge, this research is the first work revealing the contingency of social network structure in the OSS literature. Elaborately, an OSS project can be strategically attached with more structural holes in its ego-network [constructed through its shared contributors with other projects] to achieve market success, whereas the OSS project can be situated in cohesive network to advance its technical achievement. To this 
end, our finding is instrumental in strategizing the composition of OSS contributors to align with divergent expectation of OSS success, i.e. reaching out more people or quality of OSS project, in view of network structure.

Besides contributing to the OSS innovation mechanism, our findings afford evidence on how OSS project maturity plays a role in facilitating the OSS project's success through synthesizing the external resource. Elaborately, only the OSS projects, which progress from very nascent stage to developmental stage and are saturated with abundant structural holes, can benefit from maturity for market success. This rectifies previous literature that excessively esteemed the positive role of maturity in promoting OSS project success (Setia et al. 2012; Daniel et al. 2013). Our findings reveal the extent to which an OSS project can synthesize the homogenous resource is independent of its developmental stage. A potential explanation for this finding is this: In a cohesive structure such as the OSS projects, which are densely connected with each other, the circulated resource and information tend to become homogeneous and straightforward. In other words, such information can be relatively easy to assimilate, regardless of the maturity of the OSS project or contributors' experiences, which results in the insignificance of the moderation effect of maturity. Alternatively, although the mature projects with stable governance and collaborative structures might attract more contributors, those more immature ones might have more learning opportunities and more spaces for the original creation. This could also attract talented contributors. Either of these explanations resulted in the insignificant moderation role of maturity on knowledge creation. This finding is instrumental in guiding the newly established OSS project teams to the right route of OSS development by cultivating the cohesion in lieu of blind pursuit of the rate of development.

Besides contributing to the theory, an immediate practical implication of this research is that OSS project administrators may consider not only recruiting and sharing essential 
resources, such as the developers with the other projects, but also the extent to which they manage other projects. They may uncover relationships among the projects and attempt to develop connectedness with those projects by co-owning an OSS project. By being linked to or standing at the cleavage of the ego network position, projects could gain a greater diversity of information flow that, in turn, increases the popularity regarding marketing success. In considering this statement, whereas OSS projects are supposed to be user-driven, diversity in the contributors' mental models of the projects at the brokerage position may not be beneficial to technical success.

Our findings also have important implications for IT companies. In the IT industry, the leading IT companies sponsored some OSS projects to maintain a steady stream of innovation or achieve novel creations (Watson et al. 2008; Chen et al. 2012; Daniel et al. 2018). For example, IBM initiated the foundation for supporting Linux projects or Oracle invested in MySQL to expand its service lines. In this regard, our findings provided constructive suggestions for such sponsor companies to leverage the OSS project team composition to accomplish their desired outputs. In particular, for those firms that expect to achieve innovative creation by engaging the OSS community, OSS projects whose contributors (i.e., administrators or developers) coherently work in overlapped projects should be sponsored. In contrast, those firms that attempt to leverage the OSS project to promote their products or services should sponsor the OSS projects whose teams are composed of people who work in heterogeneous OSS projects.

OSS development forges, such as SourceForge.net or Github, could also benefit from our findings. In our results, the contributors' collaborative ties resulted in a trade-off between market success and technical success. In this regard, those projects with significant innovation creation achievement (i.e., high technical success) may suffer from low popularity. To resolve such a dilemma, the OSS forge operators should continuously observe 
and analyze the collaborative ties of each OSS project team and concurrently adjust their recommendation mechanism, which will effectively prevent the OSS projects with highly innovative potentials from being submerged in tremendously mediocre ones.

Our findings also shed light on the practice of open innovation in general. Unlike firms in the IT industry that have highly collaborated with the OSS community to co-create concrete products or services, the firms in conventional industries mainly leveraged open innovation for idea generation (King and Lakhani 2013). In other words, achieving an innovative output is not the main purpose of such open innovation campaigns. To this end, recruiting external innovators from different backgrounds or diversified online communities engaged in multiple and intersectional open innovation projects is recommended. Such participants' engagement will expose the focal campaign to the public to a greater extent.

\subsection{Limitations and Suggestions for Future Research}

Like any other research work, this research contains caveats of which readers should be cautious. First, this research focuses on the network metric of Burt's constraint index, which reflects the structural holes of an OSS project. These findings should be viewed cautiously when integrating them with those from other OSS studies that also adopt the network perspective but use different network metrics such as direct and indirect ties (Hahn et al. 2008; Tan et al. 2007). An immediate extension of this study is the consideration of triangulating the findings by adopting different network metrics, such as centrality and tie strength.

Second, our measurement of popularity and knowledge creation are based on the marginal differences between two periods of data collection, which enable us to temporally separate the network instantiations and the performance outcome. Although this method is the best approach with which to address commonly raised concerns (e.g., endogeneity), the interval time gap between the two periods of data collection may also raise concerns that 
relate to the continuous evolvement of the projects. Other than the researchers' judgment regarding the time gap, a primary reason is that time is required for people to know (i.e., gain interest) about a project. Different time gaps could be considered to further test the robustness of the findings. In addition, future studies could vary the weight of each component measuring the popularity and knowledge creation. The opportunities are abundant, and instead of viewing this research as deterministic and conclusive in its insights, researchers could view it as a suggestion that results in greater research ideas and inquiries.

Third, we chose to anchor our empirical investigation on SourceForge.net to align with the stream of OSS research, in which many studies use the same data source. In recent years, other OSS communities, such as Github, have emerged, and future research could consider extending this study to validate these emerging OSS communities (Medappa and Srivastava 2019). To this end, we encourage future research to verify our findings in other OSS communities.

\section{Concluding Remarks}

In nowadays, the open-source projects are more interconnected than before and cosharing valuable resources due to the emergence of OSS development forges. The findings from our analysis reveal the contingent role of the interproject connectedness [of an OSS projects' ego network structure] in the OSS project's success. Such an ego network with more structural holes, regardless of whether they are affiliated with common administrators or developers, increases the popularity of the focal OSS project. Nevertheless, for better knowledge creation, the cohesive structure (i.e., with less structural holes) is advocated. Also, we observed that the positive relationship between structural holes and popularity could be further influenced by the different maturity of the OSS projects. On the contrary, we did not observe any moderating effect of the OSS projects' development stages on the negative relationship between the extent of structural holes and knowledge creation. Leading from 
these findings, we discuss both theoretical contributions and practical implications for the

OSS development as well as organizational strategy in investing OSS projects. We

acknowledge the limitations of this study and point out intriguing directions inspiring future

research.

\section{References}

Aberdour, M. 2007. Achieving quality in open-source software. IEEE Software 24, 58-64. https://doi.org/10.1109/MS.2007.2

Ahuja, G. 2000. Collaboration networks, structural holes, and innovation: A longitudinal study. Administrative Science Quarterly 45, 425-455. https://doi.org/10.2307\%2F2667105

Austin, J. R. 2003. Transactive memory in organizational groups: the effects of content, consensus, specialization, and accuracy on group performance. Journal of Applied Psychology 88, 866-878. http://dx.doi.org/10.1037/0021-9010.88.5.866

Autio, E., Sapienza, H. J., and Almeida, J. G. 2000. Effects of age at entry, knowledge intensity, and imitability on international growth. Academy of Management Journal 43, 909-924. https://doi.org/10.5465/1556419

Balkundi, P., Kilduff, M., Barsness, Z. I., and Michael, J. H. 2007. Demographic antecedents and performance consequences of structural holes in work teams. Journal of Organizational Behavior 28, 241-260. https://doi.org/10.1002/job.428

Beckman, C. M., and Haunschild, P. R. 2002. Network learning: The effects of partners' heterogeneity of experience on corporate acquisitions. Administrative Science Quarterly 47, 92-124. https://doi.org/10.2307/3094892

Bird, C., Bachmann, A., Aune, E., Duffy, J., Bernstein, A., Filkov, V., \& Devanbu, P. 2009. Fair and balanced?: bias in bug-fix datasets. In Proceedings of the the 7th joint meeting of the European software engineering conference and the ACM SIGSOFT symposium on The foundations of software engineering (pp. 121-130). ACM. https://doi.org/10.1145/1595696.1595716

Blau, P. M. 1997. Inequality and heterogeneity: A primitive theory of social structure. New York: Free Press. https://doi.org/10.1093/sf/58.2.677

Burt, R. S. 1992. Structural hole. Cambridge, MA: Harvard Business School Press.

Chen, X., and Dietrich, G. 2009. Knowledge Location, Differentiation, Credibility and Coordination in Open Source Software Development Teams, In, $15^{\text {th }}$ Americas Conference on Information Systems (AMCIS 2009), August 6 th- $^{\text {th }}$, San Francisco, California, US, 2009.

Chen, L., Marsden, J. R., and Zhang, Z. 2012. Theory and analysis of company-sponsored value cocreation. Journal of Management Information Systems 29, 141-172. https://doi.org/10.2753/MIS0742-1222290206

Chengalur-Smith, S., and Sidorova, A. 2003. Survival of open-source projects: A population ecology perspective. In, $24^{\text {th }}$ International Conference on Information Systems (ICIS 2003), December $14^{\text {th }}$ $17^{\text {th }}$, Seattle, Washington, US, 2003.

Coad, A., Segarra, A., and Teruel, M. 2016. Innovation and firm growth: Does firm age play a role?. Research Policy 45, 387-400. https://doi.org/10.1016/j.respol.2015.10.015

Coleman, J. S. 1988. Free riders and zealots: The role of social networks. Sociological Theory, 6, 52-57. http://doi.org/10.2307/201913

Conaldi, G., Lomi, A., and Tonellato, M. 2012. Dynamic models of affiliation and the network structure of problem solving in an open source software project. Organizational Research Methods 15, 385-412. https://doi.org/10.1177/1094428111430541

Crowston, K., and Howison, J. 2006. Hierarchy and centralization in free and open source software team communications. Knowledge, Technology \& Policy 18, 65-85. https://doi.org/10.1007/s12130-006$1004-8$

Crowston, K., Howison, J., and Annabi, H. 2006. Information systems success in free and open source software development: Theory and measures. Software Process: Improvement and Practice 11, $123-$ 148. https://doi.org/10.1002/spip.259 
Crowston, K., Li, Q., Wei, K., Eseryel, U. Y., and Howison, J. 2007. Self-organization of teams for free/libre open source software development. Information and Software Technology, 49, 564-575. https://doi.org/10.1016/j.infsof.2007.02.004

Crowston, K., Wei, K., Howison, J., and Wiggins, A. 2012. Free/Libre open-source software development: What we know and what we do not know. ACM Computing Surveys 44, Article 7. https://doi.org/10.1145/2089125.2089127.

Cummings, J. N., and Cross, R. 2003. Structural properties of work groups and their consequences for performance. Social Networks 25, 197-210. https://doi.org/10.1016/S0378-8733(02)00049-7

Daniel, S., Agarwal, R., and Stewart, K. J. 2013. The effects of diversity in global, distributed collectives: A study of open source project success. Information Systems Research 24, 312-333. https://doi.org/10.1287/isre.1120.0435

Daniel, S., Midha, V., Bhattacherhjee, A., and Singh, S. P. 2018. Sourcing knowledge in open source software projects: The impacts of internal and external social capital on project success. The Journal of Strategic Information Systems, 27, 237-256. https://doi.org/10.1016/j.jsis.2018.04.002

Dong, J. Q., Wu, W., and Zhang, Y. S. 2018. The faster the better? Innovation speed and user interest in open source software. Information \& Management, 56, 669-680. https://doi.org/10.1016/j.im.2018.11.002

Eagle, N., Macy, M., and Claxton, R. 2010. Network diversity and economic development, Science 328, 1029-1031. https://doi.org/10.1126/science.1186605

Everett, M., and Borgatti, S. P. 2005. Ego network betweenness. Social Networks 27, 31-38. https://doi.org/10.1016/j.socnet.2004.11.007

Feller, J., Finnegan, P., Fitzgerald, B., and Hayes, J. 2008. From peer production to productization: A study of socially enabled business exchanges in open source service networks. Information Systems Research, 19, 475-493. http:// dx.doi.org/10.1287/isre.1080.0207

Gao, Y., and Madey, G., 2007. Network analysis of the SourceForge. net community, In, J. Feller, B. Fitzgerald, W. Scacchi, A. Sillitti. (eds.), Open Source Development, Adoption and Innovation, US, Springer US: pp. 187-200. https://doi.org/10.1007/978-0-387-72486-7 15

Garriga, H., Spaeth, S., \& Von Krogh, G. (2011, March). Open Source Software Development: Communities' Impact on Public Good. In International Conference on Social Computing, BehavioralCultural Modeling, and Prediction (pp. 69-77). Springer, Berlin, Heidelberg.

Ghosh, R. 2006. Collaborative ownership and the digital economy. Cambridge, MA: The MIT Press.

Grewal, R., Lilien, G. L. and Mallapragada, G. 2006. Location, Location, Location: How Network Embeddedness Affects Project Success in Open Source Systems. Management Science 52, $1043-$ 1056. https://doi.org/10.1287/mnsc. 1060.0550

Gargiulo, M., and Benassi, M. 2000. Trapped in your own net? Network cohesion, structural holes, and the adaptation of social capital. Organization Science, 11, 183-196. https://doi.org/10.1287/orsc.11.2.183.12514

Gulati, R., and Higgins, M. C. 2003. Which ties matter when? The contingent effects of interorganizational partnerships on IPO success. Strategic Management Journal 24, 127-144. https://www.jstor.org/stable/20060517

Hahn, J., Moon, J. Y., and Zhang, C. 2008. Emergence of new project teams from open source software developer networks: Impact of prior collaboration ties. Information Systems Research 19, 369-391. https://doi.org/10.1287/isre.1080.0192

Harrison, D. A., and Klein, K. J. 2007. What's the difference? Diversity constructs as separation, variety, or disparity in organizations. Academy of Management Review 32, 1199-1228. https://doi.org/10.5465/amr.2007.26586096

Harrison, D. A., Price, K. H., and Bell, M. P. 1998. Beyond relational demography: Time and the effects of surface-and deep-level diversity on work group cohesion. Academy of Management Journal 41, 96107. https://doi.org/10.5465/256901

Harrison, D. A., Price, K. H., Gavin, J. H., and Florey, A. T. 2002. Time, teams, and task performance: Changing effects of surface-and deep-level diversity on group functioning. Academy of Management Journal 45, 1029-1045. https://doi.org/10.5465/3069328

He, J., Butler, B. S., and King, W. R. 2007. Team cognition: Development and evolution in software project teams. Journal of Management Information Systems, 24, 261-292.

https://doi.org/10.2753/MIS0742-1222240210 
Healy, K., and Schussman, A. 2003. The ecology of open-source software development. Technical report, University of Arizona, USA. https://pdfs.semanticscholar.org/2c89/092af57b5c4508dd65863df5602c90d7bbb6.pdf

Heckman, R., Crowston, K., Eseryel, U. Y., Howison, J., Allen, E., and Li, Q., Emergent decision-making practices in free/libre open source software (FLOSS) development teams, In, , J. Feller, B. Fitzgerald, W. Scacchi, A. Sillitti. (eds.), Open Source Development, Adoption and Innovation, US, Springer US: 2007, pp. 71-84. https://doi.org/10.1007/978-0-387-72486-7 6

Holmqvist, M. 2003. A dynamic model of intra-and interorganizational learning. Organization Studies 24. 95-123. https://doi.org/10.1177/0170840603024001684

Jackson, S. E., May, K. E., and Whitney, K. 1995. Understanding the dynamics of diversity in decisionmaking team, In, Guzzo, R.A., Salas, E., and Associates, Team Effectiveness and Decision Making in Organizations, San Francisco: Jossey-Bass: 1995, 204-261.

Jiang, Q., Tan, C. H., Sia, C. L., \& Wei, K. K. 2019. Followership in an Open-Source Software Project and its Significance in Code Reuse. Mis Quarterly, 43, 1303-1319. http://doi.org/10.25300/MISQ/2019/14043.

Jones, O. 2006. Developing absorptive capacity in mature organizations: The change agent's role. Management Learning 37. 355-376. https://doi.org/10.1177/1350507606067172

Jurison, J. 1999. Software project management: the manager's view. Communications of the AIS 2, article 2. https://doi.org/10.17705/1CAIS.00217

King, A., and Lakhani, K. R. 2013. Using open innovation to identify the best ideas. MIT Sloan Management Review 55, 41-48.

Knight, D., Pearce, C. L., Smith, K. G., Olian, J. D., Sims, H. P., Smith, K. A., and Flood, P. 1999. Top management team diversity, group process, and strategic consensus. Strategic Management Journal 20, 445-465. https://doi.org/10.1002/(SICI)1097-0266(199905)20:5<445::AID-SMJ27>3.0.CO;2-V

Kuk, G. 2006. Strategic interaction and knowledge sharing in the KDE developer mailing list. Management Science 52, 1031-1042. https://doi.org/10.1287/mnsc.1060.0551

Lerner, J., and Tirole, J. 2002. Some simple economics of open source. The Journal of Industrial Economics, 50, 197-234.

Li, X., Hess, T. J., and Valacich, J. S. 2008. Why do we trust new technology? A study of initial trust formation with organizational information systems. The Journal of Strategic Information Systems 17. 39-71. https://doi.org/10.1016/j.jsis.2008.01.001

Lin, B., Robles, G., \& Serebrenik, A. (2017, May). Developer turnover in global, industrial open source projects: Insights from applying survival analysis. In 2017 IEEE 12th International Conference on Global Software Engineering (ICGSE) (pp. 66-75). IEEE.

Lindsjørn, Y., Sjøberg, D. I., Dingsøyr, T., Bergersen, G. R., and Dybå, T. 2016. Teamwork quality and project success in software development: A survey of agile development teams. Journal of Systems and Software, 122, 274-286. https://doi.org/10.1016/j.jss.2016.09.028

MacCormack, A. 2001. How internet companies build software. MIT Sloan Management Review 42. 7584.

Medappa, P. K., and Srivastava, S. C. 2019. Does Superposition Influence the Success of FLOSS Projects? An Examination of Open-Source Software Development by Organizations and Individuals. Information Systems Research, 30, 764-786. https://doi.org/10.1287/isre.2018.0829

Nerkar, A., and Paruchuri, S. 2005. Evolution of R\&D Capabilities: The Role of Knowledge Networks within a Firm, Management Science 5, 771-785. https://doi.org/10.1287/mnsc.1040.0354

Patel, P. C., Kohtamäki, M., Parida, V., and Wincent, J. 2015. Entrepreneurial orientation-asexperimentation and firm performance: The enabling role of absorptive capacity. Strategic Management Journal 36, 1739-1749. https://doi.org/10.1002/smj.2310

Paulson, L. D. 2007. Developers shift to dynamic programming languages. Computer 40, 12-15. https://doi.org/10.1109/MC.2007.53

Peng, G., Wan, Y., and Woodlock, P. 2013. Network ties and the success of open source software development. The Journal of Strategic Information Systems 22, 269-281. https://doi.org/10.1016/j.jsis.2013.05.001

Podolny, J. M., and Baron, J. N. 1997. Resources and relationships: Social networks and mobility in the workplace. American Sociological Review 62, 673-693. http://dx.doi.org/10.2307/2657354

Ren, Y., Chen, J., \& Riedl, J. 2016. The impact and evolution of group diversity in online open collaboration. Management Science 62, 1668-1686. https://doi.org/10.1287/mnsc.2015.2178 
Schoonhoven, C. B. Liability of newness, In, Cooper, C., Wiley Encyclopedia of Management, Wiley: 2015, https://doi.org/10.1002/9781118785317.weom030067

Setia, P., Rajagopalan, B., Sambamurthy, V., and Calantone, R. 2012. How peripheral developers contribute to open-source software development. Information Systems Research 23, 144-163. https://doi.org/10.1287/isre.1100.0311

Shah, S. K. 2006. Motivation, governance, and the viability of hybrid forms in open source software development. Management science, 52, 1000-1014. http://dx.doi.org/10.1287/mnsc.1060.0553

Shipilov, A.V. 2009. Firm Scope Experience, Historic Multimarket Contact with Partners, Centrality, and the Relationship Between Structural Holes and Performance. Organization Science 20, 85-106. https://doi.org/10.1287/orsc. 1080.0365

Singh, P. V. 2010. The small-world effect: The influence of macro-level properties of developer collaboration networks on open-source project success. ACM Transactions on Software Engineering and Methodology, 20, Article 6. http://doi.org/10.1145/1824760.1824763

Singh, P. V., Tan, Y., and Mookerjee, V. 2011a. Network effects: the influence of structural capital on open source project success. Management Information Systems Quarterly 35, 813-830. http://doi.org/10.2307/41409962

Singh, P. V., Tan, Y., and Youn, N. 2011b. A hidden Markov model of developer learning dynamics in open source software projects. Information Systems Research 22, 790-807. https://doi.org/10.1287/isre.1100.0308

Singh, P. V., and Tan, Y. 2010. Developer heterogeneity and formation of communication networks in open source software projects. Journal of Management Information Systems 27, 179-210. https://doi.org/10.2753/MIS0742-1222270307

Shen, C., and Monge, P. 2011. Who connects with whom? A social network analysis of an online open source software community. First Monday 16, 6, https://www.firstmonday.dk/ojs/index.php/fm/article/view/3551/2991

Smithson, M., and Verkuilen, J. 2006. A better lemon squeezer? Maximum-likelihood regression with beta-distributed dependent variables. Psychological Methods 11. 54-71. http://dx.doi.org/10.1037/1082-989X.11.1.54

Stewart, K. J., Ammeter, A. P., and Maruping, L. M. 2006. Impacts of license choice and organizational sponsorship on user interest and development activity in open source software projects. Information Systems Research, 17, 126-144. https://doi.org/10.1287/isre.1060.0082

Stewart, K. J., and Gosain, S. 2006. The impact of ideology on effectiveness in open source software development teams. MIS Quarterly 30, 291-314. http://doi.org/10.2307/25148732

Subramaniam, C., Sen, R., and Nelson, M. L. 2009. Determinants of open source software project success: A longitudinal study. Decision Support Systems 46, 576-585. https://doi.org/10.1016/j.dss.2008.10.005

Tan, Y., Mookerjee, V., and Singh, P.V., Social Capital, Structural Holes and Team Composition: Collaborative Networks of the Open Source Software Community, In, 2007 International Conference on Information Systems (ICIS 2007), December $9^{\text {th }}-12^{\text {th }}$, Montreal, Quebec, Canada: 2007.

Thon, D. 1982. An axiomatization of the Gini coefficient. Mathematical Social Sciences 2, 131-143. https://doi.org/10.1016/0165-4896(82)90062-2

Tortoriello, M. 2014. The social underpinnings of absorptive capacity: The moderating effects of structural holes on innovation generation based on external knowledge. Strategic Management Journal 36, 586597. https://doi.org/10.1002/smj.2228

Tullio, D. D., and Staples, D. S. 2013. The Governance and Control of Open Source Software Projects. Journal of Management Information Systems 30, 49-80. https://doi.org/10.2753/MIS07421222300303

Van Knippenberg, D., De Dreu, C. K. W., and Homan, A. C. 2004. Work group diversity and group performance: An integrative model and research agenda. Journal of Applied Psychology 89, 10081022. http://doi.org/10.1037/0021-9010.89.6.1008

Van Knippenberg, D., and Schippers, M. C. 2007. Work group diversity. Annu. Rev. Psychol. 58, 515-541. https://doi.org/10.1146/annurev.psych.58.110405.085546

von Hippel, E., and von Krogh, G. 2003. Open source software and the "private-collective" innovation model: Issues for organization science. Organization Science 14, 209-223. https://doi.org/10.1287/orsc.14.2.209.14992

Wasserman, S., and Faust, K. 1994. Social network analysis: Methods and applications (Vol. 8), Cambridge, UK: Cambridge University Press. https://doi.org/10.1017/CBO9780511815478 
Watson, R. T., Boudreau, M. C., York, P. T., Greiner, M. E., and Wynn Jr, D. 2008. The business of open source. Communications of the ACM 51, 41-46. https://doi.org/10.1145/1330311.1330321

Wen, W., Forman, C., and Graham, S. J. 2013. Research note-The impact of intellectual property rights enforcement on open source software project success. Information Systems Research 24. 1131-1146. https://doi.org/10.1287/isre.2013.0479

Wooldridge, J. M. Econometric analysis of cross section and panel data, Cambridge, US: MIT Press, 2010.

Woolley, A. W., Chabris, C. F., Pentland, A., Hashmi, N., and Malone, T. W. 2010. Evidence for a Collective Intelligence Factor in the Performance of Human Groups. Science 330, 686-688. https://doi.org/10.1126/science.1193147

Xiao, Z., and Tsui, A. S. 2007. When brokers may not work: The cultural contingency of social capital in Chinese high-tech firms. Administrative Science Quarterly 52, 1-31. https://doi.org/10.2189/asqu.52.1.1

Zaheer, A., and Soda, G. 2009. Network evolution: The origins of structural holes. Administrative Science Quarterly, 54, 1-31. http://doi.org/10.2189/asqu.2009.54.1.1

Zahra, S. A., and George, G. 2002. Absorptive capacity: A review, reconceptualization, and extension. Academy of Management Review 27. 185-203. https://doi.org/10.2307/4134351

Zahra, S. A., and Hayton, J. C. 2008. The effect of international venturing on firm performance: The moderating influence of absorptive capacity. Journal of Business Venturing 23. 195-220. https://doi.org/10.1016/i.jbusvent.2007.01.001

Zhu, K. X., and Zhou, Z. Z. 2012. Research note-Lock-in strategy in software competition: Open-source software vs. proprietary software. Information Systems Research 23, 536-545.

https://doi.org/10.1287/isre.1110.0358 